\title{
MARGIN CALLS, TRADING COSTS, AND ASSET PRICES IN EMERGING MARKETS: THE FINANCIAL MECHANICS OF THE 'SUDDEN STOP' PHENOMENON
}

\author{
Enrique G. Mendoza \\ Katherine A. Smith \\ Working Paper 9286 \\ http://www.nber.org/papers/w9286
NATIONAL BUREAU OF ECONOMIC RESEARCH 1050 Massachusetts Avenue
Cambridge, MA 02138 \\ October 2002
}

\begin{abstract}
We thank Fernando Alvarez, Cristina Arellano, Leonardo Auernheimer, Guillermo Calvo, Larry Christiano, Daniele Coen-Pirani, Jonathan Heatcote, Urban Jermann, Amartya Lahiri, Fabrizio Perri, Tony Smith, Diego Valderrama, Kirk White and Stan Zin for helpful comments and suggestions. The views expressed herein are those of the authors and not necessarily those of the National Bureau of Economic Research.

(C) 2002 by Enrique G. Mendoza and Katherine A. Smith. All rights reserved. Short sections of text, not to exceed two paragraphs, may be quoted without explicit permission provided that full credit, including (C) notice, is given to the source.
\end{abstract}


Margin Calls, Trading Costs, and Asset Prices in Emerging Markets: The Financial Mechanics of the 'Sudden Stop' Phenomenon

Enrique G. Mendoza and Katherine A. Smith

NBER Working Paper No. 9286

October 2002

JEL No. F41, F32, E44, D52

\begin{abstract}
A central feature of emerging markets crises is the "Sudden Stop" phenomenon characterized by large reversals of capital inflows and current accounts, deep recessions, and collapses in asset prices. This paper proposes an open-economy asset-pricing model with financial frictions that yields predictions in line with these observations. Margin requirements and information costs distort asset trading between a small open economy and foreign securities firms. If the economy's debt-equity ratio is low, standard productivity shocks cause normal recessions with smooth current-account adjustments. If the ratio is high, the same productivity shocks trigger margin calls forcing domestic agents to firesell equity to foreign traders who are slow to adjust their portfolios. This sets off a Fisherian asset-price deflation and subsequent rounds of margin calls. A current account reversal and a collapse in consumption occur if the fire-sale of assets cannot prevent a sharp increase in net foreign asset holdings.
\end{abstract}

Enrique G. Mendoza

Department of Economics

University of Maryland

College Park, MD 20742

and NBER

mendozae@econ.umd.edu
Katherine A. Smith

Duke University

Durham, NC 27708 


\section{Introduction}

A significant fraction of the literature dealing with the waves of economic and financial crises affecting emerging economies since the 1990s focuses on an intriguing phenomenon that Calvo (1998) labeled a "Sudden Stop." This phenomenon is defined by three key features: sudden, sharp reversals in capital inflows and current account deficits, large downward adjustments in domestic production and absorption, and collapses in asset prices and in the relative prices of nontradable goods relative to tradables.

Calvo and Reinhart (1999) examine the features of Sudden Stops and compare them with previous crisis episodes in emerging markets. Their findings show that while the empirical regularities of Sudden Stops resemble a typical "contractionary devaluation," the changes in capital flows and the collapses in the real sector of the economy largely exceed those observed in previous balance-of-payments crises of developing nations. Mendoza (2002) shows that in the case of Mexico the Sudden Stop of 1995 resulted in a recession and a collapse in domestic relative prices that largely exceeded the recession phase of a regular Mexican business cycle.

The collapses in equity prices, current account reversals and deep recessions that occur when a Sudden Stop takes place are striking. Table 1 summarizes these stylized facts using quarterly data for four well-known cases. In the Mexican crisis, equity prices fell more than 50 percent, the current account rose by 5.2 percentage points of GDP and industrial output fell nearly 10 percent. Argentina experienced contagion via the so called "Tequila Effect," and this

resulted in a fall of 27 percent in asset prices, a current account reversal of 4 percentage points of GDP and a collapse in industrial output similar to Mexico's. Korea's Sudden Stop in the Fall of 1997 stands out for its major current account reversal of almost 11 percent of GDP. Equity 
prices fell by 35 percent and in the other East Asian countries hit by Sudden Stops at the same time they fell by at least 20 percent (as in Hong Kong). Russia also experienced a large current account reversal and large collapse in asset prices of nearly 60 percent. These Sudden Stops also induced higher asset price volatility. The volatility of weekly emerging-market dollar returns doubled from 2 to 4 percent during the 1997 East Asian crisis and the 1998 Russian crisis. ${ }^{1}$

There is growing consensus among researchers and policymakers in the view that financial-market imperfections are an important factor in explaining Sudden Stops. ${ }^{2}$ The theoretical literature has made progress in developing economic models in which financial frictions can cause Sudden Stops but little is known about the quantitative predictions that this class of models delivers. In particular, there is no quantitative evidence showing whether these models can produce endogenous Sudden Stops with features similar to those of Sudden Stops observed in the data and without recurring to exogenous shocks to the economy's ability to access international capital markets. This paper aims to address these issues by developing an open-economy equilibrium asset-pricing model distorted by financial frictions and exploring its quantitative implications for explaining Sudden Stops.

The model considers two financial frictions widely emphasized in studies of emerging markets crises (see the survey by Arellano and Mendoza (2002)): (1) collateral constraints, in the form of a margin requirement that limits the ability of an emerging economy to use domestic

\footnotetext{
${ }^{1}$ These figures are means of rolling 13-week standard deviations of equity price indexes in U.S. dollars for 16 emerging markets (see Figure 3.8 in International Monetary Fund (1999)).

${ }^{2}$ An incomplete list of research papers that follow this approach includes Auernheimer and Garcia (2000), Aghion, Baccheta and Banerjee (2000), Caballero and Krishnamurty (1999), Calvo (1998), Calvo and Mendoza (2000a), Mendoza (2002), Paasche (2001), Cespedes, Chang and Velasco (2001), Schneider and Tornell (20001) and Christiano, Gust and Roldos (2002).
} 
equity to leverage foreign debt, and (2) asset trading costs, intended to capture the effects of informational or institutional frictions affecting the ability of foreign traders to trade the equity of emerging economies. These frictions interact with the economic forces at work in equilibrium stochastic asset pricing models (uncertainty, risk aversion and incomplete insurance markets) to conform an environment in which Sudden Stops can occur as an endogenous response to productivity shocks of the same magnitude that drive regular business cycles in a frictionless real-business-cycle model.

The transmission mechanism that causes Sudden Stops in the model operates as follows. When the economy is in a state of nature with a "sufficiently high" ratio of debt to equity, an adverse productivity shock has an effect that it does not have in other states: it triggers margin calls. These margin calls force domestic residents to fire-sell assets to foreign securities firms, ${ }^{3}$ which are slow to adjust their portfolios because of the trading costs they incur. As a result, equilibrium asset prices fall. This price fall triggers a new round of margin calls setting off a Fisherian asset-price deflation as domestic agents engage in further fire sales of assets to comply with increasingly tight margin requirements. ${ }^{4}$ If the fire sale of assets is not enough to prevent a large adjustment in total net foreign asset holdings, the margin calls result in sudden reversals of capital inflows and the current account and a sudden drop in private consumption. That is, a Sudden Stop takes place. Interestingly, echoing a result in Aiyagari and Gertler (1999), current equity prices fall whenever agents expect margin constraints to bind in the future with some

${ }^{3}$ This is a "fire sale" in the sense that domestic agents rush to adjust their equity position below the position they would optimally hold in the absence of margin constraints.

${ }^{4}$ The idea of the Fisherian asset-price deflation is developed in Fisher (1933). A similar argument can also be found in Keynes (1932). 
probability, even if they do not bind at present.

The analysis of this financial transmission mechanism as a feature of the competitive equilibrium of a dynamic, stochastic general equilibrium model of asset pricing with risk averse agents and incomplete markets is a difficult task. Equilibrium equity prices are forward looking objects that represent matching expected present values of the stream of dividends discounted with the equilibrium sequences of intertemporal marginal rates of substitution of different agents. These marginal rates of substitution vary depending on whether margin calls take place or not, and this in turn depends on the current equilibrium price of equity. Thus, equilibrium dynamics feature a nonlinear feedback between equity prices, effective discount rates, and margin constraints. The paper develops a numerical solution method to explore these nonlinear dynamics using the recursive representation of the models' competitive equilibrium.

The transmission mechanism triggering Sudden Stops in this paper differs in some important respects from the "financial accelerators" examined in a large fraction of the literature on emerging markets crises, particularly those based on the closed-economy models of credit cycles of Kiyotaki and Moore (1997) and Bernanke, Gertler and Girlchrist (1998). The model of this paper differs in that it introduces elements of equilibrium asset-pricing theory in the presence of non-insurable risk, collateral constraints and trading costs that result in important differences in the effects that financial frictions have on the economy. Existing Sudden Stops models with collateral constraints feature borrowing constraints that are always binding along an equilibrium path, or that are imposed as a sudden, unanticipated shock on an economy that had until then enjoyed access to perfect capital markets. In contrast, the model examined here features collateral constraints that become binding in states of nature with debt-equity ratios high enough 
to trigger endogenous margin calls once the state of productivity is realized. Thus, collateral constraints are only occasionally binding and agents are allowed to formulate optimal plans factoring in the possibility of observing these states. Moreover, in contrast with models that adopt the Bernanke-Gertler setup of costly monitoring, in which the external financing premium is unaffected by aggregate risk and behaves as a smooth function of the net worth-debt ratio of the economy, the equilibrium dynamics of the model of this paper are influenced by noninsurable risk and the risk premium exhibits sudden jumps when margin calls occur.

The asset-pricing features of the model proposed in this paper are similar to those studied in some of the closed-economy equilibrium asset pricing literature, particularly in Aiyagari (1993), Lucas (1994), Heaton and Lucas (1996), Krusell and Smith (1997) and Aiyagari and Gertler (1999). These authors examined the asset-pricing implications of margin requirements, borrowing constraints, trading costs and short-selling constraints in order to determine if these frictions could explain the classic financial puzzles of U.S. capital markets, particularly the equity premium puzzle. The quantitative results of these studies were mixed but the financial frictions they proposed can still be important for explaining Sudden Stops. Empirical regularities like the equity premium puzzle relate to long-run features of the data and moments of the limiting distribution of a model economy (on which the literature found that financial frictions produce small effects). In contrast, Sudden Stops are features of equilibrium dynamics when "occasionally binding" financial frictions become binding even if in the limiting distribution they remain rare events.

Occasionally binding financial constraints and an explicit link between asset prices and macroeconomic dynamics can also be important for understanding other key aspects of Sudden 
Stops. First, as argued in Mendoza (2002), these features may provide a means to account for Sudden Stops as rare but violent episodes that are nested within regular business cycles. Second, they may provide an explanation for the temporarily large international asset return differentials associated with an emerging economy's sudden loss of access to international capital markets. Third, to the extent that foreign shocks like a world-interest-rate shock can trigger margin calls, models of this class embody a financial transmission mechanism for the international spillover or "contagion" of capital markets crises. ${ }^{5}$ Fourth, since occasionally binding credit constraints can lead to distorted asset prices even in states in which the constraints do not bind (as long as they may become binding in the future), they can offer an explanation for the higher volatility of emerging-markets asset prices relative to industrial-country prices even if actual Sudden Stops are rare.

The rest of the paper proceeds as follows. Section 2 presents the structure of the model, defines the competitive equilibrium in recursive form, and discusses the transmission mechanism driving Sudden Stops. Section 3 reviews key properties of the deterministic version of the model. Section 4 develops the numerical solution method and reports simulation results. Section 5 concludes.

\section{An Open-Economy Equilibrium Asset Pricing Model with Financial Frictions}

The model can be viewed as an equilibrium asset pricing model with heterogeneous

${ }^{5}$ The contagion episode after the Russian default in 1998 offers an interesting example. During this episode, margin calls were triggered across emerging markets by rising estimates of potential losses produced by the value-at-risk models of investment banks that leveraged hedge funds like Long Term Capital Management. As volatility increased and asset prices fell, valueat-risk estimates worsened mandating even larger margin calls. Similarly, in the model, a foreign real shock that triggers an initial margin call leads to a fall in equity prices that induces even larger margin calls. 
agents and financial frictions. One set of agents is modeled as a representative-agent small open economy subject to non-diversifiable productivity shocks. The residents of this economy are risk averse and trade bonds and equity with the rest of the world. They face a margin requirement that limits their ability to borrow and a standard short-selling constraint on their equity holdings. The second set of agents is represented by the rest of the world, which is in turn made of two entities: a global credit market, in which one-period bonds are traded and the world's real interest rate is determined, and a set of foreign securities firms specialized in holding equity of the small open economy. These firms face higher costs than domestic residents in adjusting their portfolios due to their disadvantaged trading position that may result from institutional features or informational frictions (see Frankel and Schmukler (1996) and Calvo and Mendoza (2001)). ${ }^{6}$

The margin requirements and trading costs modeled here are similar to those proposed by Aiyagari and Gertler (1999). They examined a closed-economy setting in which households face portfolio adjustment costs, securities firms face margin requirements, and income and consumption (and thus the risk-free real interest rate) are driven by exogenous random processes. $^{7}$ In contrast, in the small-open-economy model examined here domestic households are the agents facing margin requirements, foreign traders are subject to trading costs, and consumption and income are endogenous.

${ }^{6}$ Note that this can be the case regardless of the location in which trading takes place. For instance, emerging-markets securities traded in New York (i.e., ADR's) may still be traded in an environment in which trading orders placed by residents of emerging markets reflect better information or smaller effective trading costs than those placed by nonresidents.

${ }^{7}$ Coen-Pirani (2000) shows that in a heterogeneous-agents variation of the AiyagariGertler model, in which agents differ in their degree of risk aversion, margin requirements lower the risk-free rate and increase its volatility but do not alter equity prices. The Aiyagari-Gertler case with an exogenous risk-free rate is more in line with the situation of a small open economy. 


\subsection{Domestic Firms}

There is a large number of identical firms in the small open economy which produce a single tradable good using a variable labor input $\left(L_{t}\right)$ and a fixed supply of capital $(K)$. Firms produce this good using a constant-returns-to-scale (CRS) technology $\exp \left(g_{t}\right) F\left(K, L_{t}\right)$, where $g_{t}$ is a Markov productivity shock. The markets for the final good and labor are competitive, so firms choose labor demand in order to maximize profits:

$$
\exp \left(\varepsilon_{t}\right) F\left(K, L_{t}\right)-w_{t} L_{t}
$$

The optimization problem of firms takes this basic static form because there is no capital accumulation. As shown later, this simplifying assumption, combined with specific assumptions about the structure of preferences introduced below, yields equilibrium sequences of labor, wages and dividends that are determined separately from the equilibrium dynamics of consumption, portfolio choices and asset prices. If capital accumulation were added but firms were assumed to have unrestricted access to global financing, the firms' problem would again reduce to a seemingly-static problem but portfolio decisions and the "supply-side" of the model would no longer be separated.

Labor demand for $t=0, \ldots, 4$ is given by the standard marginal productivity condition:

$$
\exp \left(\varepsilon_{t}\right) F_{L}\left(K, L_{t}\right)=w_{t}
$$

Dividend payments for $t=0, \ldots, 4$ are thus given by:

$$
d_{t}=\exp \left(\varepsilon_{t}\right) F_{K}\left(K, L_{t}\right)
$$

Productivity shocks follow a two-point, symmetric Markov chain. This specification minimizes the size of the exogenous state space without restricting the variance and first-order 
autocorrelation of the shocks. The shocks take high $(H)$ or low $(L)$ values, so the exogenous state space is defined by $E=\left\{g_{H}, g_{R}\right\}$. Symmetry implies that $q=-g_{H}$, and that the long-run

probabilities of each state satisfy $A(g)=A\left(g_{t}\right)=1 / 2$. The transition probabilities are set by the “simple persistence” rule (see Backus, Gregory and Zin (1989)):

$$
\begin{aligned}
& \pi_{\varepsilon_{i} \varepsilon_{j}}=(1-\vartheta) \Pi\left(\varepsilon_{j}\right)+\vartheta \mathrm{I}_{\varepsilon_{i} \varepsilon_{j}}, \\
& \mathrm{I}_{\varepsilon_{i} \varepsilon_{j}}=1 \text { if } i=j \text { and } 0 \text { otherwise, for } i, j=L, H .
\end{aligned}
$$

Under these assumptions, the shocks have zero mean, their variance is $\left(g_{H}\right)^{2}$, and their serial autocorrelation coefficient is given by $h$.

\subsection{Households}

A large number of identical, infinitely-lived households inhabit the small open economy. Their preferences are represented by Esptein's (1983) Stationary Cardinal Utility (SCU) function with an endogenous subjective rate of time preference:

$$
U=E\left[\sum_{t=0}^{\infty} \exp \left\{-\sum_{\tau=0}^{t-1} v\left(C_{\tau}-G\left(L_{\tau}\right)\right\} u\left(C_{t}-G\left(L_{t}\right)\right)\right]\right.
$$

With these preferences, the lifetime marginal utility of date-t consumption includes an "impatience effect," by which a change in $C_{t}$ alters the subjective discount rate that applies to the entire future utility stream. The period utility function $u$ is a standard continuously differentiable, concave utility function that satisfies $u\left(@ 0, u^{\prime}\left(@ 0, u^{\prime}(0)=4\right.\right.$, and $\ln (-u(@$ convex. The timepreference function $v$ must satisfy $v\left(@ 0, v^{\prime}\left(@ 0, v^{\prime \prime}\left(@ 0\right.\right.\right.$, and $u^{\prime}(@ x p(v) @$ nonincreasing. These conditions are easy to satisfy using standard functional forms such as a Constant Relative Risk Aversion (CRRA) period utility function and a logarithmic time-preference function. The argument of the $u$ and $v$ functions is the composite commodity $C-G(L)$ defined by Greenwood, 
Hercowitz and Huffman (1988), or GHH. $G(L)$ is a concave, continuously differentiable function that measures the disutility of labor. The GHH composite good neutralizes the wealth effect on labor supply by making the marginal rate of substitution between consumption and labor supply depend on the latter only. This makes labor supply decisions independent of consumption, saving and portfolio allocation choices.

Intertemporal preferences with endogenous impatience have a long history in the analysis of the dynamics of small open economies (see Obstfeld (1982) and Mendoza (1991)). They play a central role in stochastic models because in these models the precautionary saving motive implies that the standard assumption of setting a fixed rate of time preference equal to the world's interest rate fails to produce a well-defined stochastic stationary equilibrium (as foreign asset holdings still diverge to infinity in the long run).

Preferences with a fixed rate of impatience can support a well-defined stochastic steady state only if the rate of interest is set lower than the rate of time preference arbitrarily. In this case, however, the mean foreign asset position is largely determined by the assumed difference between the two rates. Other alternatives that can address this stationarity problem impose adhoc functional forms relating the world interest rate to foreign debt or the rate of time preference to average consumption, but these are serious departures from microfoundations and whether they can yield solutions equivalent to the preferable alternatives can only be determined case by case. In contrast, Epstein (1983) showed that a Von Neumann-Morgenstern intertemporal utility function satisfies standard preference axioms for choice under uncertainty (generalized to include an axiom requiring preferences over random future consumption to be independent of nonrandom current consumption) if and only if the utility function takes the form of the SCU 
function. Thus, the microfoundations of SCU rule out ad hoc choices regarding the specification of the time-preference function. Moreover, the conditions linking the $u$ and $v$ functions imply quantitatively small impatience effects, so that these effects do not play an important role in the short-run dynamics of the model.

Households maximize SCU subject to the following period budget constraint:

$$
C_{t}=\alpha_{t} K d_{t}+w_{t} L_{t}+q_{t}\left(\alpha_{t}-\alpha_{t+1}\right) K-b_{t+1}+b_{t} R
$$

where " ${ }_{t}$ and ${ }_{t+1}$ are beginning- and end-of-period shares of the domestic capital stock owned by domestic households, $b_{t}$ and $b_{t+1}$ are holdings of one-period international bonds, $q_{t}$ is the price of equity, and $R$ is the world's gross real interest rate (which is kept deterministic for simplicity).

In addition to the budget constraint, households face a margin requirement according to which they cannot borrow more than a fraction 6 of the value of assets offered as collateral:

$$
b_{t+1} \geq-\kappa q_{t} \alpha_{t+1} K, \quad 0 \leq \kappa \leq 1
$$

This is an "ex ante" collateral constraint that differs in three key respects from "ex post" collateral constraints (which limit debt not to exceed the discounted one-period-ahead liquidation value of the collateral, as with the Kiyotaki-Moore constraint). First, with a margin clause custody of the collateral is surrendered to the lender at the time the debt contract is entered. Second, margin calls are automatically triggered by declines in the market value of the collateral, giving lenders the option to liquidate the collateral assets if borrowers fail to meet margin calls. Third, the borrowing limit depends on current equity prices, rather than on expected prices for one period in the future. These properties imply that margin constraints are not affected by some of the strategic issues often raised in connection with other collateral constraints, related to whether countries have efficient institutions to enforce the repossession and liquidation of assets 
in cases of default and to whether this is even optimal for lenders once they reach a default state. It is also worth noting that margin clauses are widely used in international capital markets and take different forms, ranging from explicit margin clauses imposed by lenders or regulatory agencies to implicit margin clauses like those implied by the investment banks' use of value-atrisk models.

Households also face a constraint setting a minimum equity position ${ }_{t} \$ P$ for $-4<P<1$ and $t=1, \ldots, 4$. This constraint is a short-selling constraint if $P \# 0$, while $0<P<1$ can be interpreted as a portfolio requirement. The latter is worth considering because "is the share of the domestic capital stock owned by domestic residents, which is known to display a high degree of home bias in the data. The constraint ${ }_{t} \$ P$ is needed to ensure that the state space of portfolio holdings is compact and that the margin requirement is not irrelevant. If unlimited short selling of equity were possible, domestic agents could always undo the effect of the margin constraint. The lower bound on equity also serves to support well-behaved equilibria as in other general-equilibrium, incomplete-markets models of asset trading because of the potential for the portfolio ${ }^{\prime \prime}+b_{t}$ to become unbounded otherwise (see Judd, Kubler and Schmedders (2000)).

The first-order conditions of the optimization problem of domestic residents are:

$$
\begin{gathered}
U_{C_{t}}(\cdot)=\lambda_{t} \\
G^{\prime}\left(L_{t}\right)=w_{t} \\
q_{t}\left(\lambda_{t}-\eta_{t} \kappa\right)=E_{t}\left[\lambda_{t+1}\left(d_{t+1}+q_{t+1}\right)\right]+v_{t} \\
\lambda_{t}-\eta_{t}=E_{t}\left[\lambda_{t+1} R\right]
\end{gathered}
$$

$U_{C_{t}}\left(\right.$ Adenotes the lifetime marginal utility of date-t consumption, and $\mathcal{B}_{t}, O_{t}$, and $L_{t}$ are the 
nonnegative multipliers on the budget constraint, the margin constraint, and the constraint on the lower bound on equity respectively. In addition to conditions (8)-(11), the first-order conditions include the three constraints and the Kuhn-Tucker conditions associated with each constraint.

The above first-order conditions have straightforward interpretation, with the caveat of the impatience effects on marginal utility. The optimal labor supply condition in (9) shows the effect of the GHH composite good: the marginal disutility of labor is set equal to the real wage without any intertemporal effects. Conditions (10) and (11) are Euler equations for the accumulation of equity and foreign bonds. Since by definition the return on equity is $R_{t+1}^{q} /\left(d_{t+1}+q_{t+1}\right) / q_{t}$, these conditions can be combined to derive the following expression for the expected premium on the return of domestic equity vis-a-vis international bonds:

$$
E_{t}\left[R_{t+1}^{q}\right]-R=\frac{\eta_{t}(1-\kappa)-\frac{v_{t}}{q_{t}}-\operatorname{COV}_{t}\left(\lambda_{t+1}, R_{t+1}^{q}\right)}{E_{t}\left[\lambda_{t+1}\right]}
$$

If the margin and short-selling constraints never bind (i.e., $O_{t}=L_{t}=0$ for all $t$ ), this expression yields the standard result for the equity premium of a frictionless asset-pricing model. In contrast, a binding margin requirement at date $t$ (i.e., $O_{t}>0$ ) induces an "excess" equity premium because of the pressure that the margin call exerts on households to fire-sell equity, depressing the current equity price. This "direct effect" of the margin constraint on the equity premium is limited to the fraction $(1-6)$ of the shadow value $O_{t}$ because a binding margin requirement increases the marginal benefit of increasing equity holdings by the fraction $\sigma$ (i.e., increased demand for equity helps households to relax the borrowing constraint). A binding short-selling constraint increases the marginal gain of increasing equity holdings and has no effect on the marginal benefit of saving in foreign assets, hence it reduces the equity premium. 
The rest of this Section derives analytical results for the effects of margin calls and trading costs on asset prices assuming internal solutions for equity holdings (i.e., $L_{t}=0$ ).

The effect of the binding margin constraint at $t$ is likely to be persistent because, as shown later in this Section, households trying to liquidate equity to meet margin calls trade with foreign traders that are slow to adjust their portfolios because of trading costs. Moreover, as in Aiyagari and Gertler (1999), the equity premium formula in (12) can yield the result that excess equity returns may exist whenever it is possible for a margin call to occur in the future, even if the margin requirement does not bind at present. These two results follow from the "indirect effect" of the margin requirement, by which the conditional covariance between $\boldsymbol{8}_{t+1}$ and $R_{t+1}^{q}$ in the right-hand-side of (12) is likely to become more negative when margin calls are possible than with a perfect credit market. This occurs in turn because the risk of a binding borrowing limit at $t+1$ hampers the ability of households to smooth consumption, leading to precautionary saving, increased consumption volatility and a lower covariance between consumption and equity returns (i.e., $\boldsymbol{8}_{t+1}$ rises while $R_{t+1}^{q}$ falls). ${ }^{8}$ The intuition is that equity is a bad hedge against the risk of margin calls because the more negative the covariance between these two variables, the more likely it is that margin calls coincide with low ex-post equity returns. Households will thus demand a larger equity premium to reflect this unhedged risk.

To analyze further the effects of the margin constraint on equity prices, the Euler equation for equity holdings (equation (10)) is solved forward to yield the following expression:

${ }^{8}$ This is the Heaton-Lucas "indirect effect of trading costs" on asset prices, which occurs "to the extent that the increase in consumption volatility increases the covariance between individual consumption and the net return on stock" (Heaton and Lucas (1996), p. 465). 


$$
q_{t}=E_{t}\left(\sum_{i=0}^{\infty}\left[\prod_{j=0}^{i}\left(\frac{\lambda_{t+j}}{E_{t+j}\left[\lambda_{t+1+j} R\right]+\eta_{t+j}(1-\kappa)}\right)\right] M_{t+1+i} d_{t+1+i}\right)
$$

where $M_{t+1+i} / 8_{t+1+i} / 8_{t}$ for $i=0, \ldots, 4$, is the stochastic intertemporal marginal rate of substitution between $C_{t+1+i}$ and $C_{t}$. If the margin requirement never binds, this expression collapses again to the standard asset-pricing formula. In the case that margin calls are possible at any date, the rates at which future dividends are discounted in the valuation of asset prices by domestic agents are altered by the direct and indirect effects mentioned above. The effect on the price of equity is easier to interpret by solving forward the expression $E_{t}\left[R_{t+1}^{q}\right]=E_{t}\left[\left(d_{t+1}+q_{t+1}\right) / q_{t}\right]$ to obtain:

$$
q_{t}=E_{t}\left(\sum_{i=0}^{\infty}\left[\prod_{j=0}^{i}\left(E_{t}\left[R_{t+1+j}^{q}\right]\right)^{-1}\right] d_{t+1+i}\right)
$$

where the sequence of $E_{t}\left[R_{t+1+j}^{q}\right]$ is given by (12). Hence, if the direct and indirect effects of margin calls on intertemporal plans lead to excess equity returns, a margin requirement that is binding at present or expected to bind in the future implies that some or all of the expected equity returns used to discount the future stream of dividends in the above asset-pricing formula increase, and thus the current price of equity bid by households falls.

\subsection{Foreign Securities Firms}

Foreign securities firms specialize in holding equity of the small open economy. These firms maximize the present discounted value of dividends paid to their global shareholders, facing transactions costs that are quadratic in the size of trades (as in Aiyagari and Gertler 
(1999)) and in a fixed recurring cost. ${ }^{9}$ These transactions costs represent the disadvantaged position from which foreign traders operate relative to domestic agents when trading domestic equity. This disadvantage may result from informational frictions (i.e., domestic residents may be better informed on economic and political variables relevant for determining the earnings prospects of local firms),$^{10}$ or because of country-specific institutional features or government policies that favor domestic residents. The recurring cost represents an entry cost for participating in an emerging equity market that is also intended to reflect informational and operational costs that foreign traders incur to remain able to trade in emerging-markets instruments, even if they do not actually trade in a particular period. Section 3 shows that this recurring cost helps the model support deterministic long-run equilibria in which margin requirements bind and asset prices deviate from "fundamentals" permanently.

Foreign securities firms choose ${ }^{\prime *}{ }_{t+1}$ for $t=0, \ldots, 4$ so as to maximize: ${ }^{11}$

$$
D=E_{0}\left[\sum_{t=0}^{\infty} M_{t}^{*}\left(\alpha_{t}^{*} K\left(d_{t}+q_{t}\right)-q_{t} \alpha_{t+1}^{*} K-q_{t}\left(\frac{a}{2}\right)\left(\left(\alpha_{t+1}^{*}-\alpha_{t}^{*}+\theta\right) K\right)^{2}\right)\right], \quad \theta, a \geq 0
$$

${ }^{9}$ Transactions costs are generally modeled as quadratic on the value of the trade (see Heaton and Lucas (1996)). The Aiyagari-Gertler specification, in which the equity price enters in linear form, yields a more tractable recursive specification of the trader's optimal behavior.

${ }^{10}$ Foreign traders may be less informed simply because they cannot access or process country-specific information as easily as domestic agents or because they optimally choose not to do so. Calvo and Mendoza (2000b) provide two arguments for why the latter can be the case. First, with limited short-selling, a foreign investor's utility gain of paying information costs falls as the number of emerging markets in which to invest grows. Second, if portfolio manager's face performance-based incentives with marginal punishments larger than rewards, there is a range of multiple optimal portfolios in which managers simply mimic each other's behavior.

${ }^{11}$ International bond holdings by securities firms are not modeled for simplicity. If these firms are small in the bond market and do not face borrowing constraints (other than a no-Ponzigame condition), the optimality condition for equity holdings remains unaltered. Analyzing the case in which they face margin requirements is an important task for further research. 
where $M_{0}^{*} / 1$ and $M_{t}^{*}$ for $t=1, \ldots, 4$ are the exogenous marginal rates of substitution between date- $t$ consumption and date- 0 consumption for the world's representative consumer. Trading costs are given by the term $q_{t}(a / 2)\left[\left({ }^{\prime *}{ }_{t+1^{-}}{ }^{\prime *}{ }_{t}+2\right) K\right]^{2}$. The recurring entry cost is 2 and the parameter $a$ is a coefficient governing marginal trading costs.

At an interior solution, the first-order conditions for the above optimization problem imply that the foreign traders' demand for the emerging economy's assets follows a partial adjustment rule of the form:

$$
\left(\alpha_{t+1}^{*}-\alpha_{t}^{*}\right) K=a^{-1}\left(\frac{q_{t}^{f}}{q_{t}}-1\right)-\theta
$$

where $q^{f}{ }_{t}$ is the "fundamentals" price of equity defined as:

$$
q_{t}^{f} \equiv E_{t}\left(\sum_{i=0}^{\infty} M_{t+1+i}^{*} d_{t+1+i}\right)
$$

According to (16), foreign traders increase their demand for equity by a factor $1 / a$ of the percent deviation of the date-t fundamentals price above the actual price (i.e., the price elasticity of their demand for equity is $1 / a$ ). Thus, the informational or institutional frictions behind the trading costs drive the partial-adjustment behavior of traders and are key to support equity prices below fundamentals levels. If foreign traders did not incur trading costs, their demand for equity would be infinitely elastic and domestic agents could liquidate the shares needed to meet margin calls at an infinitesimal discount of the fundamentals price.

The equity demand function of the foreign traders reflects their assessment of the values at which they are willing to hold a particular position on the emerging economy's assets, which can be compared with the assessments made by domestic residents reflected in the asset-pricing 
$-18-$

equations (13) and (14). One important element in comparing these assessments are differences in the foreign and domestic stochastic discount factors $M^{*}{ }_{t+1+i}$ and $M_{t+1+i}$ for $i=0, . .4$. This would not be an issue under perfect foresight because at equilibrium both would equal the reciprocal of the world's real interest rate compounded $i$ periods. Under uncertainty, however, this is not the case even with an exogenous, risk-free world interest rate. The domestic stochastic discount factors are endogenous and reflect the effects of margin calls on consumption and saving. The foreign traders' stochastic discount factors are exogenous and are set so that foreign securities firms discount returns at the discount rate of the world's representative consumer, which is assumed to be equal to $R$ (i.e., $\left.M_{t+1+i}{ }^{*} / R^{i}\right){ }^{12}$

\subsection{Equilibrium}

Given the probabilistic process of productivity shocks and the initial conditions $\left(b_{0},{ }_{0},{ }^{\prime \prime}{ }^{*}\right)$, a competitive equilibrium is defined by sequences of state-contingent allocations $\left[C_{t}, L_{t}, b_{t+1},{ }^{\prime \prime}{ }_{t+1},{ }^{\prime \prime}{ }_{t+1}^{*}\right]_{t=0}{ }^{4}$ and prices $\left[w_{t}, d_{t}, q_{t}, R_{t}^{q}\right]$ such that: (a) domestic firms maximize dividends subject to the CRS production technology, taking factor and goods prices as given, (b) households maximize SCU subject to the budget constraint, the margin constraint, and the shortselling constraint, taking as given factor prices, goods prices, the world interest rate and the price of equity, (c) foreign securities firms maximize the expected present value of dividends net of trading costs, taking as given equity prices, and (d) the market-clearing conditions for equity, labor, and goods markets hold.

${ }^{12}$ Another alternative is to assume that $M^{*}{ }_{t+1+i}$ equals the values of $M_{t+1+i}$ for a version of the model without any financial frictions. The intuition is that in this environment the domestic economy is one of many similar small open economies. This yields a "no trading equilibrium" in which equity positions are stationary and $q_{t}=q_{t}^{f}$ for all $t$. Domestic agents smooth consumption and undertake precautionary saving by trading in the bond market. 
The competitive equilibrium is solved for by reformulating it in recursive form and applying a recursive numerical solution method. To represent the equilibrium in recursive form, define " and $b$ as the endogenous state variables and $\varepsilon$ as the exogenous state. The state space of equity positions spans the discrete interval $\left[\chi, \alpha^{\max }\right]$ with NA elements and the state space of debt position spans the discrete interval $\left[b^{\min }, b^{\max }\right]$ with NB elements. The endogenous state space is thus defined by the discrete set $Z=\left[\chi, \alpha^{\max }\right] \times\left[b^{\min }, b^{\max }\right]$ of NAxNB elements. Note also that since equilibrium wages, dividends and factor payments depend only on $\varepsilon$, they can be expressed by the functions $w(\varepsilon), d(\varepsilon)$ and $L(\varepsilon)$ that solve jointly equations (2), (3) and (9).

Assume a continuous, nonnegative equity pricing function $q(\alpha, b, \varepsilon): E \times Z \rightarrow R^{+}$that is taken as given by foreign traders and the small open economy. For any initial state ( ",b,e) this conjectured pricing function must satisfy $q(\alpha, b, \varepsilon) \in\left[q^{\min }(\alpha, \varepsilon), q^{\max }(\alpha, \varepsilon)\right]$, where $q^{\min }(\alpha, \varepsilon)=q^{f}(\varepsilon) /[1+a(\alpha-\chi+\theta)]$ and $q^{\max }(\alpha, \varepsilon)=q^{f}(\varepsilon) /\left[1+a\left(\alpha-\alpha^{\max }+\theta\right)\right]$ are the maximum and minimum equity prices along the foreign traders' demand curve for an initial state with equity holdings " and productivity shock $g$ These bounds of the pricing function follow from the fact that when equity holdings of the small open economy hit either $\chi$, or $\alpha^{\max }$, the foreign traders' price prevails because they are at the "short side" of the market (assuming the equity demand curves of both players are well-behaved with the one of the foreign traders always flatter than that of the small open economy).

Imposing market clearing in the equity market, the conjectured pricing function and the 
foreign trader's partial-adjustment decision rule imply the following conjectured transition equation for equilibrium equity holdings:

$$
\hat{\alpha}^{\prime}(\alpha, b, \varepsilon)=\alpha-\frac{1}{a} *\left(\frac{q^{f}(\varepsilon)}{q(\alpha, b, \varepsilon)}-1\right)+\theta
$$

Taking as given the conjectured asset transition and pricing functions, and the equilibrium functions for factor payments and labor allocations, one can define the following dynamic programming problem for the small open economy:

$$
\begin{aligned}
& V(\alpha, b, \varepsilon)= \\
& \max _{b^{\prime}}\left\{\frac{\left[c-\frac{n(\varepsilon)^{\delta}}{\delta}\right]^{1-\sigma}-1}{1-\sigma}+\exp \left(-\beta\left[\operatorname{Ln}\left(1+c-\frac{n(\varepsilon)^{\delta}}{\delta}\right)\right]\right) E\left[V\left(\hat{\alpha}^{\prime}(\alpha, b, \varepsilon), b^{\prime}, \varepsilon^{\prime}\right)\right]\right\}
\end{aligned}
$$

subject to:

$$
\begin{aligned}
& c=\alpha k d(\varepsilon)+w(\varepsilon) n(\varepsilon)+q(\alpha, b, \varepsilon) k\left[\alpha-\hat{\alpha}^{\prime}(\alpha, b, \varepsilon)\right]-b^{\prime}+b R \\
& b^{\prime} \geq-\kappa q(\alpha, b, \varepsilon) \hat{\alpha}^{\prime}(\alpha, b, \varepsilon) k
\end{aligned}
$$

The solutions of this problem represent the small open economy's optimal consumption and bond accumulation choices for any given conjectured pricing function and equity transition equation. These optimal plans can then be applied to the asset pricing formulas in (13) to compute the domestic agents' pricing function, $\tilde{q}(\alpha, b, \varepsilon)$, which shows the asset prices at which the small open economy would agree to the trades implicit in the conjectured pricing and equity transition equations in a competitive equity market. In general, for an arbitrary initial conjectured pricing function and associated asset transition equation, the conjectured pricing function and the pricing function of domestic agents will differ. The numerical solution method updates the conjectured pricing function using a Gauss-Seidel algorithm and iterates repatedly 
until the distance between the two functions satisfies a standard convergence criterion.

The pricing function and the decision rules obtained after the pricing functions converge constitute a recursive competitive equilibrium for the model. In a recursive equilibrium, the optimal rules determining equity holdings, bond holdings, consumption, labor, wages, dividends, foreign equity holdings and the equity pricing function are such that: (a) given equity prices, wages and dividends, the policy functions for $c, b N$ "Nand $L$ solve the maximization problems of households and firms in the small open economy, (b) given equity prices and dividends, the policy function for " $\mathbb{N}$ solves the maximization problem of foreign traders, and (c) the marketclearing conditions for equity, goods and labor markets hold.

Proving that the prices and allocations obtained once the conjectured and domestic pricing functions converge satisfy the above conditions is straightforward. First, note that the Benveniste-Sheinkman equation applied to problem (19) yields the same Euler equation for bond holdings as the households maximization problem. Second, by construction, the domestic equity pricing function ensures that the households' Euler equation for equity holdings also holds (up to the error allowed by the convergence criterion). Third, wages, dividends and labor allocations are drawn from the functions $w(\varepsilon), d(\varepsilon)$ and $L(\varepsilon)$ and thus satisfy the optimality conditions for labor supply, labor demand and dividends. Fourth, the conjectured asset transition equation ensures that the optimality condition of foreign traders holds. Finally, the constraints of the Bellman equation in (19), combined with the previous four results, ensure that the market clearing conditions, the households' budget constraint, and the margin constraint are satisfied.

\section{Perfect Foresight Implications}

The model's deterministic equilibrium delivers interesting predictions regarding the 
effects of margin requirements and trading costs on asset prices and portfolio choice. It also provides the conditions used to calibrate the model for numerical analysis in the next Section. Under perfect foresight, the emerging economy's equity premium and asset pricing equations (12) and (13) reduce to:

$$
\begin{gathered}
R_{t+1}^{q}-R=\frac{\eta_{t}(1-\kappa)}{\lambda_{t+1}} \\
q_{t}=\sum_{i=0}^{\infty}\left(\prod_{j=0}^{i}\left[1+(1-\kappa) \frac{\eta_{t+j}}{\lambda_{t+j}-\eta_{t+j}}\right]^{-1} R^{-i} d_{t+1+i}\right)
\end{gathered}
$$

As these expressions show, there is an equity premium under perfect foresight only if the margin requirement binds at date $t$ and this premium reflects only the direct effect of margin calls.

These results are useful to show that the margin constraint has asset-pricing effects similar to those of the collateral constraint in Kiyotaki and Moore (1997), or KM. The KM constraint would require $R b_{t+1} \$-q_{t+1}{ }^{\prime \prime}{ }_{t+1} K$. This constraint yields the following forward solution for equity prices (using $O$ now for the multiplier on the $\mathrm{KM}$ constraint):

$$
q_{t}=\sum_{i=0}^{\infty}\left[1-\frac{\eta_{t+i}}{\lambda_{t+i}}\right]^{-1} R^{-i} d_{t+1+i} .
$$

Thus, the KM constraint is similar to a margin requirement in that (a) if the constraint binds the equity price is lower than the fundamentals price because of the higher effective real interest rate that households face with a binding borrowing constraint, ${ }^{13}$ and (b) if the constraint can be binding in the future, the current equity price is lower than the fundamentals price. The differences in the product terms of (21) and (22) indicate, however, that the quantitative

\footnotetext{
${ }^{13}$ Note that the Euler equation for bonds (eq. (10)) implies that $0 \# 1-0,18_{t} \# 1$.
} 
implications of the two constraints differ. In turn, those product terms differ because a margin requirement binding at $t$ alters the discount rates domestic agents apply to dividends and capital gains at $t+1$, while a binding KM constraint alters only the discount rate applied to dividends.

Consider next the implications of margin requirements and trading costs for the deterministic steady state. The long-run fundamentals equity price equals the present value of steady-state dividends discounted at the world interest rate. The foreign traders' demand function implies a steady-state equity price $\bar{q}=\bar{q}^{f} /(1+a \theta) \leq \bar{q}^{f}$ and therefore the return on equity is $\bar{R}^{q}=1+(\bar{d} / \bar{q}) \geq \bar{R}$.

The above results imply that a necessary condition for the steady-state equity price to equal its fundamentals level, and for the equity premium to vanish in the long run, is that there are no recurring trading costs (i.e., $2=0$ ). However, for this equity price to satisfy the domestic agents' Euler equations for equity and bonds it must be the case that the margin constraint does not bind. The asset pricing condition (21) implies then that domestic agents agree to the equilibrium equity price $\bar{q}=\bar{q}^{f}=\bar{d} /(\bar{R}-1)$. In this case, there is a unique level of steady-state consumption independent of initial conditions determined by the condition $\exp (v(\bar{C}))=\bar{R}$. The stock of saving, $\bar{S} \equiv \bar{b}+\bar{q} \bar{\alpha}$, also has a unique steady state because savings and consumption are related by the budget constraint $\bar{C}=\bar{w} \bar{L}+\bar{S}(\bar{R}-1)$. The steady-state portfolio composition is undetermined, however, because any equity position that satisfies $\chi \leq \bar{\alpha} \leq \bar{S} /\left((1-\kappa) \bar{q}^{f}\right)$ can be supported as a steady state with the corresponding bond position set to obtain the unique level of steady-state saving. A steady-state equilibrium does not exist for either smaller equity holdings, because the short-selling constraint would not hold, or larger equity holdings, because this would 
make the margin constraint bind (which cannot happen at steady state when $2=0$ ).

It is worth noting that, with $2=0$, reducing 6 reduces the maximum domestic equity position that can be supported at steady state. Thus, the model predicts that economies with lower margin coefficients would display lower degrees of "home bias" (i.e., lower ") in the long run, but not because of efficient financial arrangements. The reduced home bias is needed to ensure that the margin requirement does not bind.

In the case in which $2>0$, the foreign traders' problem yields a steady-state equity price lower than the fundamentals price and a long-run equity premium equal to $2 a(R-1)$. This outcome can be supported as a steady state on the households' side because the endogenous rate of time preference allows the rate of impatience to increase to match the equity premium. The domestic steady-state equity position is now $\quad \bar{\alpha}=\bar{S} /((1-\kappa) \bar{q})$. Domestic agents hold more equity than in the case with $2=0$ because of (a) a "quantity effect" (i.e., the margin constraint increases long-run saving) and (b) a "price effect" (the equity price falls below $q^{f}$ ). The long-run composition of the portfolio is now uniquely determined and is independent of initial conditions.

These results show that recurring trading costs and domestic preferences with endogenous impatience are both necessary for the margin constraint to bind in a deterministic stationary state. The results also suggest that long-run binding credit constraints can offer a potential explanation for a long-run "home bias" in portfolio holdings. For a given coefficient 6 , recurring trading costs increase home bias by increasing the quantity and price effects of the margin constraint. These effects are stronger the higher are 2 or $a$ because higher values of these parameters imply a lower long-run equity price, a larger premium on domestic equity, and higher steady-state saving. 


\section{Numerical Analysis of the Stochastic Competitive Equilibrium}

The stochastic model does not yield closed-form solutions that can be used to study the dynamics of the competitive equilibrium so the analysis proceeds using numerical methods. This Section proposes and implements an algorithm for computing the recursive competitive equilibrium and presents numerical results illustrating the model's ability to account for the main features of Sudden Stops.

\subsection{Solution Method}

The algorithm proposed below is designed keeping in mind the need to handle four key characteristics of the model: the incompleteness of financial markets, the two-dimensional portfolio choice in a two-agent competitive equilibrium setting, the forward-looking nature of equity prices, and the endogenous inequality constraint represented by the margin requirement. The algorithm combines features of the solution methods proposed by Lucas (1994), Heaton and Lucas (1996), Judd et al. (2000), and Krusell and Smith (1997).

As in Lucas (1994) and Heaton and Lucas (1996), equilibrium asset prices are determined by an iterative procedure analogous to a "Tatonnment" process. Their approach iterates on the quantities of assets that different agents wish to trade, seeking to converge to a market-clearing outcome. The method used here is similar but it iterates on prices instead of quantities. The algorithm iterates on the conjectured and domestic asset pricing functions described in Section 2 until they satisfy a stopping rule. In the model of this paper, this procedure is more efficient than iterating on the quantities because it takes advantage of the fact that the model has a closed-form solution for the foreign traders demand for equity. By using this closed-form solution and the conjectured pricing function to create the conjectured equity transition equation, the algorithm 
simplifies the domestic economy's Bellman equation so that domestic agents choose the bond position instead of both equity and bonds.

The algorithm differs from the Heaton-Lucas algorithm in that optimal portfolios are not forced to be drawn from the nodes that make up discrete grids of bonds and equity positions. Instead, following Judd et al. (2000), optimal portfolios are chosen from a continuous approximation to the endogenous state space $Z$. This avoids the extra transactions costs that are added implicitly by forcing portfolio decision rules to correspond exactly to grid points. Since policy functions exhibit kinks because of the borrowing and short-selling constraints, the approximation to a continuous state space is based on interpolations of the value function (as in Krusell and Smith (1997)) instead of approximations of the policy functions. The value function is interpolated using bi-linear interpolation over the nodes of the discrete grids that define $Z$ so as to ensure continuity of the interpolants. The value function is examined to ensure that bi-linear interpolation preserves concavity.

The algorithm proceeds in the following steps:

1. Select functional forms and parameter values for the problems of households, domestic firms and foreign securities firms, and for the Markov process of productivity shocks.

2. Specify the value of the lower bound on equity and construct discrete grids containing the interpolation nodes for the endogenous state space: ( ", b) $0 Z=\left[P,{ }^{\prime \max }\right] \mathrm{x}\left[b^{\min }, b^{\max }\right]$. The space of initial states is therefore defined by all triples ( ", $b, g$ ) in the discrete set $Z x E$.

3. Propose an initial conjectured pricing function $q(", b, g)$-- the fundamentals equity price is generally used as the initial conjecture.

4. Combine the conjectured pricing function with the foreign traders' demand function and the equity market-clearing condition to create the conjectured transition equation (equation (18)).

5. Solve the small open economy's dynamic programming problem (19) via value-function iteration. The initial states are given by ( ", $b, g) 0 \mathrm{Zx} E$ but the maximization step approximates the one-step-ahead value function in the rigth-hand-side of (19) using bilinear interpolation so that the approximate decision rule $b \mathbb{N}^{\prime \prime}, b, g$ ) can be chosen off grid nodes. This decision rule is determined by solving for the optimal bond position that satisfies the first-order condition of the dynamic programming problem using the bi-linear 
approximation to the value function within the interpolation nodes included in $Z x E$.

6. Check the margin constraint for each $b \mathbb{N}^{\prime \prime}, b, g$ at each pass of the maximization step.

The constraint is assumed to be nonbinding first, but if the resulting $b \mathbb{N}^{\prime \prime}, b, g$ violates the constraint, the constraint is imposed with equality. That is, when the constraint binds the decision rule for bonds is the closed form $b^{\prime}(\alpha, b, \varepsilon)=-\kappa q(\alpha, b, \varepsilon) \hat{\alpha}^{\prime}(\alpha, b, \varepsilon)$, for the pricing conjecture $q\left(\right.$ " $, b, g$ and the associated equity transition function $\hat{\alpha}^{\prime}(\alpha, b, \varepsilon)$.

7. Value function iterations continue until convergence is attained.

8. Use the optimal decision rule $b \mathbb{N}^{\prime \prime}, b, g$ to compute optimal consumption plans, the multipliers on the margin constraint, and the domestic equity pricing function given by equation (13). If the domestic and conjectured equity pricing functions satisfy the stopping rule $\sup \left(\frac{|q(\alpha, b, \varepsilon)-\tilde{q}(\alpha, b, \varepsilon)|}{1+q(\alpha, b, \varepsilon)}\right) \leq \xi$ for some small $\rightarrow$ a recursive equilibrium for the model has been found. If the rule fails, update the conjectured pricing function and return to Step 4. Updates of the pricing function for iteration $i+1$ follow this Gauss-

Siedel algorithm: $q^{i+1}(\alpha, b, \varepsilon)=\omega^{i}(\alpha, b, \varepsilon)\left[\tilde{q}^{i}(\alpha, b, \varepsilon)-q^{i}(\alpha, b, \varepsilon)\right]+q^{i}(\alpha, b, \varepsilon)$, where $T(", b, g)$ is a coefficient set to dampen unstable price iterations $(T<1)$ or accelerate convergence of stable ones $(T>1)$ using an adaptive successive overrelaxation (ASOR) procedure that combines data from iterations $i$ and $i-1$. This is necessary because iterations on pricing functions do not follow a contraction mapping and work instead by searching for a fixed point on the "Tatonnement" process. Without ASOR, this process may not converge due to the well-known problem of unstable "hog cycles."

\subsection{Functional Forms and Calibration}

The functional forms adopted to represent preferences and technology are as follows::

$$
\begin{gathered}
F\left(K, L_{t}\right)=K^{1-\gamma} L_{t}^{\gamma}, \quad 0 \leq \gamma \leq 1 \\
u\left(C_{t}-G\left(L_{t}\right)\right)=\frac{\left[C_{t}-G\left(L_{t}\right)\right]^{1-\sigma}-1}{1-\sigma}, \quad \sigma>1 \\
v\left(C_{t}-G\left(L_{t}\right)\right)=\beta\left[\operatorname{Ln}\left(1+C_{t}-G\left(L_{t}\right)\right)\right], \quad 0<\beta \leq \sigma \\
G\left(L_{t}\right)=\frac{L_{t}^{\delta}}{\delta}, \quad \delta>1
\end{gathered}
$$

The parameter ( is the share of output allocated to labor payments, $F$ is the coefficient of relative risk aversion, $\$$ is the elasticity of the rate of time preference with respect to $1+C_{t}-G\left(L_{t}\right)$ 
and $*$ determines the wage elasticity of labor supply (which is equal to $1 /\left(*_{-} 1\right)$ ). The condition $0<\$ \# F$ is required to satisfy the conditions identified by Epstein (1983) to ensure that SCU yields well-behaved dynamics.

The algorithm needs values for the vector of parameters $J=\left[\left(, F, \$,{ }^{*}, R, g_{t}, h, 6, P, a, 2\right]\right.$. In addition, the algorithm requires an upper bound for the grid of equity holdings "max , boundaries for the grid of foreign bonds $\left(b^{\min }, b^{\max }\right)$, and the interior nodes of the discrete grids of bond and equity. The values of several parameters are set using the calibration technique typical of real business cycle (RBC) theory that relates parameter values to observed empirical regularities. Setting values for the financial frictions parameters $(6, P, a, 2)$ is more difficult. Margin requirements and short-selling constraints actually at work in international capital markets are a combination of government regulations and private contractual practices. Similarly, actual trading costs are a mixture of pecuniary costs and economic costs that is difficult to measure. Hence, the numerical analysis starts from a baseline calibration in which an RBC-like calibration exercise sets the values of the parameters $\left(\left(, F, \$,{ }^{*}, R, g_{t}, h\right)\right.$, while the values of $(\sigma, P, a, 2)$ are set so that the margin constraint is not binding in all of $Z x E$. The value of 6 is then lowered to trigger margin calls in a subset of the state space so as to explore the model's ability to produce Sudden Stops.

The RBC calibration exercise follows Mendoza (2002), which sets parameter values for a two-sector model with similar utility and production functions to replicate empirical regularities taken from Mexican data. Mexico is a good subject for the numerical analysis because it represents an emerging economy with an open capital account that went through a typical Sudden Stop in 1994-95. 
The average share of payments to labor in GDP at current prices for the period 1988-96 from Mexico's System of National Accounts yields a value (=0.341. Mexico's average GDP shares of consumption, net exports, investment and government expenditures at current prices for the period 1970-95 from the World Bank's Development Indicators are 0.684, 0.007, 0.217, and 0.092 respectively. For the model to mimic the consumption- and net exports-GDP ratios in a deterministic stationary state, it is necessary to introduce adjustments to allow for investment and government expenditures. The calibration assumes that government expenditures are financed with a constant consumption tax set at $J=0.092 / 0.684=0.135$, which is very close to Mexico's actual value-added tax rate. This tax washes out from the Euler equations but it does distort labor supply. Still, keeping the tax rate state- and time-invariant implies that its effects on the stochastic dynamics are minimal. To control for investment expenditures, the calibration adds an autonomous level of private expenditures equal to the share of steady-state output absorbed by private investment.

Without loss of generality, the capital stock is set at $K=1$. Lacking precise information on the wage elasticity of labor supply, the calibration assumes unitary elasticity, so * $=2$. Given the parameters $\left(, K, J\right.$ and ${ }^{*}$, the steady-state allocations of labor and output and the associated wage and dividend rates are computed using the production function in (23) and the optimality conditions (2), (3) and (9), adjusted for the presence of the consumption tax.

The coefficient of relative risk aversion and the gross real interest rate are set to standard RBC values $F=1.1$ and $R=(1.065)^{1 / 4}$. The real interest rate and the dividend rate determine the steady-state fundamentals asset price $q^{f}=d /(R-1)=32.4$. Similarly, steady-state consumption is calculated using steady-state output and the requirement that the consumption-GDP ratio matches 
the average from Mexican data (0.684). Given $C, L$ and ${ }^{*}$, the value of $\$$ is derived from the steady-state Euler equation for bonds, which implies $\$=\operatorname{Ln}(R) / \operatorname{Ln}\left(1+C-L^{*} /^{*}\right)=0.04518$.

The Markov process of productivity shocks is set so that the standard deviation and firstorder autocorrelation of these shocks matches the standard deviation and first-order autocorrelation of the quarterly cyclical component of Mexico's tradables GDP. In terms of the simple persistence rule defined in (4), this implies $g_{H}=0.0336$ and $h=0.553$.

The values of the parameters governing financial frictions $(6, \mathrm{P}, 2, a)$ are set as follows. Recall first that in this baseline calibration the margin constraint must not bind at any point in the state space, including the deterministic stationary equilibrium. The results from Section 3 show that this requires $2=0$. The value of $a$ is then set so as to yield a high price elasticity for the foreign traders' demand curve. The elasticity is set at 200, which implies $a=0.005$. This ensures that trading costs also have a negligible effect on the equilibrium of the baseline calibration.

Thus, the results for the baseline calibration approximate a version of the model without financial frictions (i.e., no margin requirements on domestic agents and very low trading costs paid by foreign traders). Given the values of $a$ and 2 and setting ${ }^{\prime \prime m a x}=1$, the results of Section 3 imply a range of values for 6 that supports a deterministic steady state with nonbinding margin requirements: $6 \$ 1-\left(S / q^{f}\right)=0.011 .^{14}$ Finally, the value of $P$ is set at 0.5 , so that foreign ownership of the domestic capital stock is not allowed to exceed 50 percent.

The emerging economy's steady-state net foreign asset position, ["- 1$] q^{f} K+b$, can now be

${ }^{14}$ Since in this case there is a unique steady state for saving $S="{ }^{f} K+b$ but the composition of the portfolio is undetermined (any $P \#^{\prime \prime} \#^{\prime \prime m a x}$ and $b=S$ - " $q{ }^{f} K$ is consistent with the steady state), the range for 6 is set so as to support a steady state at "max. This value of 6 would therefore support a steady state with nonbinding margin requirements for any $P \#^{\prime \prime} \#^{\prime \max }$. 
computed given $K=1, q^{f}=32.4$, and Mexico's average trade balance-GDP ratio of 0.007 . Steady state net foreign assets are about -43.7 percent of output, which is in line with the calculations for Mexico reported by Lane and Milesi-Ferretti (2002). However, in this deterministic stationary state debt positions in bonds (i.e., $b<0$ ) exist only for values of " between 0.99 and 1 . The reason is that lower equity positions imply that foreign equity holdings take a larger share of the negative overall net foreign asset position of the emerging economy, hence increasing its steadystate bond holdings. In terms of the data, however, the fact that emerging countries' debt bears a large risk premium suggests that their debt instruments are more keen to equity than to riskless debt, so the relevant figure to match with the model is the net foreign asset position rather than the portfolio composition in terms of equity and debt.

Before reviewing the simulation results, note that because of precautionary saving effects and the direct and indirect effects of margin calls, the deterministic stationary state used to calibrate the model is likely to differ widely from the first moments of the limiting distributions of bonds and equity. Hence, the deterministic steady state is useful for imposing some discipline in the manner in which parameter values are selected but it is not a good predictor of the mean values of " and $b$ in the stochastic steady state.

\subsection{Simulation Results}

The quantitative analysis compares the equilibrium of the nearly-frictionless baseline calibration with the case in which the parameters of financial frictions are reset to trigger margin calls. The grid of bond holdings has 130 evenly-spaced nodes spanning the interval [-3.06,6.54]. The equity grid has 76 evenly-spaced nodes spanning the interval $[0.5,1.0]$. With the financial frictions parameters set at $a=0.005,2=0$ and $P=0.5$, a value of $\sigma$ set at $\sigma=0.92$ is sufficient for 
the margin constraint to be non-binding over the entire state space $Z x E$. Lower values of 6 can also produce this result because the threshold value of 6 in the deterministic steady state is only 0.011. The accuracy of the simulations is evaluated by computing the error in the pricing functions, defined as the absolute value of differences between the conjectured and domestic pricing functions as a percent of the former (see Judd et al. (2000)). After 250 iterations on the pricing functions, the average error was 0.007 percent and the largest error was 1 percent. This compares favorably with average errors of up to 0.4 percent in Heaton and Lucas (1996).

The variant of the baseline calibration that introduces occasional margin calls lowers 6 to 0.009, which is slightly below the threshold value of the deterministic steady state. In this case, the emerging economy cannot borrow more than 0.9 percent of the market value of its equity holdings. However, since the price of equity is relatively high (fluctuating around the 32.4 value of the deterministic steady state), this low value of 6 still allows the economy to sustain high levels of debt (of up to37 percent of GDP).

Figures 1 and 2 plot the bond and equity decision rules in the low productivity state for the emerging economy with and without margin requirements. Figures 3, 4 and 5 show the corresponding equity prices, the premium on the emerging market's equity relative to the world interest rate, and the "real" debt-equity ratio (i.e., the ratio $\left.-b N^{\prime \prime}, b, g /{ }^{\prime \prime} N{ }^{\prime \prime}, b, g\right)$ ). For the plots with margin requirements, the triangular area around the coordinates $(0,0)$ - which corresponds to $\left(P, b^{\min }\right)$ since the axis are labeled using the counters of the bond and equity grids - is irrelevant because for such low values of $\alpha$ and $b$ the non-negativity constraint on $C-G(L)$ and the margin constraint cannot be jointly satisfied. In these and the other three-dimensional Figures, the plots shows values for this triangular area that correspond to the lowest $(\alpha, b)$ pair for which a 
feasible value for the variable being plotted exists.

Figures 1 to 5 illustrate how portfolio decisions and asset prices differ across economies with and without margin requirements. In the absence of margin calls, the model produces standard results. Portfolio decision rules display typical properties: $b \mathbb{N}^{\prime \prime}, b, g$ and " $\mathbb{N}$ ", $b, g$ ) are increasing in " and $b$ and yield stable dynamics that produce the ergodic distributions plotted in Figure 6. There is also very little volatility in equity prices and negligible equity premia, and the debt-equity ratio is a well-behaved function of the state variables that increases smoothly as $b$ falls. All these results are turned around in the economy with margin requirements.

For the region of the state space in which the debt-equity ratio would pass above 29 percent, the state of low productivity triggers margin calls. As explained in Section 2, the initial margin call leads domestic agents to fire-sale equity to foreign traders, and since the demand for equity of the latter is less than perfectly elastic, the price of equity falls. This leads to subsequent rounds of margin calls and a Fisherian asset-price deflation in which asset prices fall while at the same time domestic agents are reducing their debt exposure and equity holdings. The Figures do not capture this within-period dynamics because they plot equilibrium prices and allocations that are the end result of the Fisherian deflation. Figure 2 shows that if the emerging economy is at

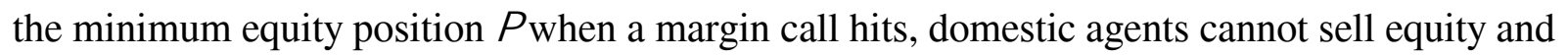
hence their debt position remains constant and the price of equity cannot fall (see Figs. 1 and 3). For relatively low levels of initial equity holdings but above $P$, the emerging economy fire-sales all the equity it can, yielding the largest equity price collapses and debt position corrections. For relatively high initial equity holdings, the emerging economy meets the margin calls without reducing its equity holdings to $P$, so the equity price collapse and the correction in the debt 
position are less severe. ${ }^{15}$

The asset price collapses in the region of margin calls deviate sharply from the smooth price adjustments produced by the economy without margin requirements. Still, the price collapses themselves are quantitatively small because of the low trading costs assumed in the calibration (which imply a high demand elasticity for the foreign traders' demand curve). For the same reason, equity premia remain small relative to observed equity premia even though they are much larger than those produced by the economy without margin requirements. These excess returns display the same pattern of the asset price collapses. They are the largest when the domestic economy liquidates the largest amount of equity to meet margin calls.

The values of consumption and the current account-output ratio in the region of margin calls can differ markedly from those of the economy without margin requirements depending on the above pattern of asset trading. If the economy has a relatively high initial equity position, the levels of consumption and the current account in the two economies do not differ much despite the active asset trading and large movements in prices. In fact, the asset trading activity reflects the domestic agent's relatively successful efforts at minimizing the effects of the margin calls and the Fisherian asset-price deflation on consumption. However, if the initial equity position is low, consumption in the economy with margin requirements can be more than 7 percent below that in the economy without margin requirements and the current account-GDP ratio can be up to 3

\footnotetext{
${ }^{15}$ This change in portfolio composition also reflects the relative cost of using equity or bonds to smooth consumption. In the absence of margin requirements, equity trading costs lead to intensive trading in bonds (which can be traded at no cost). In contrast, binding margin requirements produce a state-contingent pattern of asset trading. If debt is low, bonds are again traded more actively than equity, but if the economy is highly leveraged the trade-off can change abruptly in favor of equity.
} 
percentage points higher.

The above comparisons of prices and allocations for economies with and without margin requirements across the entire state space reflect the model's ability to generate Sudden Stops in response to an unexpected, once-and-for-all regime change in world capital markets (i.e., a fall in the value of 6). This is analogous to the thought experiment in Christiano et al. (2002), in which a borrowing constraint is suddenly imposed on a small open economy, except that here whether the change in 6 triggers or not a Sudden Stop depends on the debt-equity ratio of the economy when the regime switch takes place. Moreover, the magnitude of the Sudden Stop also varies with the initial state as this determines the size of the fire sale and the Fisherian deflation of asset prices. Still, this account of Sudden Stops is incomplete in as much as it starts from the assumption of an exogenous regime change in international capital markets.

The simulation results can be used to conduct a different experiment in which Sudden Stops emerge endogenously, without assuming an exogenous regime change in international capital markets. To examine this possibility, compare the impact effects on consumption and the current account-GDP ratio of a shift from the high to the low states of productivity. Figures 7 and 8 plot these impact effects for a subset of coordinates $(", b)$ in $Z$ that captures the margin calls region. The productivity shocks are the same zero-mean, 3.3 percent standard-deviation shocks regardless of the initial states of debt and equity, but the impact effects for the economy with margin requirements differ sharply from those of the economy without margin requirements. Without margin requirements, the impact effects are consumption declines ranging between 1.8 and 2.8 percent and widening current account deficits of the order of 2.5 to 5 percentage points of GDP. In contrast, the collapse in consumption in the economy with margin calls can reach 9.2 
percent and the current account-GDP ratio moves in the opposite direction (with reversals as large as 1.6 percentage points of GDP). Consumption is generally more volatile in the economy with margin calls, but domestic agents still manage to fire-sale assets and adjust their debt position in a manner such that consumption remains relatively smooth if they hold enough equity when the margin calls hit. Margin calls result in large drops in consumption and current account reversals only when equity holdings are too small relative to the debt position. As before, equity price corrections and asset liquidations observe the opposite ordering. In states in which the impact effect on consumption is moderate, equity price collapses and sales of equity by domestic agents are much larger than to those observed in states in which consumption falls sharply.

The limiting distributions plotted in Figure 6 suggest that the endogenous Sudden Stops described above are rare events, since states in which " and $b$ are at levels such that a productivity shock can trigger a Sudden Stop have a very low long-run probability of occurrence. This result follows from the aversion of domestic agents to a volatile consumption profile, which drives them to undertake precautionary saving, require a risk premium on equity in most states, and fire sale assets to meet margin calls. Even without margin calls, the model is prone to have domestic agents sell equity at equilibrium in any state in which they demand an equity premium because (with $2=0$ ) foreign traders always buy equity at prices that reflect this premium (i.e., at prices below $q_{t}^{f}$ ). Domestic agents then seek to provide for self-insurance by building up a large enough bond position. These trends show in the high probability of low equity positions and high bond positions in the ergodic distribution of the economy without margin requirements.

The fire-sales of assets that take place in the economy with margin calls exacerbate the above effects and result in an ergodic distribution for equity that is more biased towards low 
equity positions and an ergodic bond distribution with zero probability of high debt levels. The highest debt positions (i.e., $b$ less than the 36th point in the bonds grid, or $b<-0.454$ ) are ruled out by a version of Aiyagari's (1994) natural debt limit: since there is a non-zero long-run probability of visiting states with low equity holdings (including " $=P$, domestic agents must hold a minimum amount of bonds such that they are not exposed to the possibility of $C-G(L)$ becoming non-positive along any stochastic equilibrium path.

These findings provide an interesting interpretation of the dynamics of emerging economies off and on the stochastic stationary equilibrium, which is relevant to consider because the creation of emerging equity markets is a recent event (dating back to the late 1980s) that took place in an environment of high external debts. The simulation results suggest that during the early periods of this financial globalization emerging economies would be highly vulnerable to suffer endogenous Sudden Stops in response to seemingly "normal” productivity shocks. Economies that go through these early periods with favorable realizations of the state of nature can reach the area of debt-equity ratios in which Sudden Stops are very unlikely. During this same stage the model also predicts high excess returns on emerging markets equity.

All of the simulation results presented above are robust to the addition of a small recurring trading cost on foreign traders set at $2=0.001$. The only significant difference is in the shapes of the ergodic distributions of equity and bonds (see Figure 6). The presence of the recurring trading cost implies at equilibrium that domestic agents will hit the lower bound in equity holdings more often in the long run and this translates into stronger precautionary-saving incentives affecting bond holdings. However, these effects do not translate into significant differences in the equilibrium prices and allocations reviewed for the simulations with $2=0$. 


\section{Conclusions}

This paper explores whether the stylized facts of the Sudden Stops phenomenon observed in emerging markets crises can be rationalized as the outcome of a stochastic, generalequilibrium asset pricing model for a small open economy with financial frictions. The underlying source of uncertainty in the model are standard productivity shocks that domestic agents cannot hedge against because asset markets are assumed to be incomplete. Two sets of financial frictions are considered. First, domestic residents face a collateral constraint in international debt markets in the form of a margin requirement. Second, foreign traders face trading costs that reflect institutional or informational frictions they encounter in trading the equity of the small open economy. In this environment, domestic agents make optimal saving and portfolio allocation plans influenced by risk aversion and precautionary saving.

The paper proposes a numerical solution method that solves the competitive equilibrium of the model in recursive form. Numerical simulations illustrate the potential for the interaction of margin calls and trading costs to trigger Sudden Stops in two ways. First, as a result of unexpected, permanent changes in exogenous world credit market conditions that tighten margin constraints. Second, as an endogenous outcome induced by negative productivity shocks of standard magnitude in a particular region of the state space in which equity holdings are small relative to external debt.

Analysis of the stochastic stationary state suggests that Sudden Stops are dramatic but rare events which economies can outgrow as they build up their net foreign asset position. This is an interesting finding in light of the fact that emerging equity markets were created only a decade ago and in an environment in which emerging economies were highly indebted. The 
$-39-$

model predicts that in this early stages emerging economies are vulnerable to Sudden Stops even in the absence of systemic shocks to world capital markets, and that in these same early stages emerging economies will command large excess returns,

Margin calls have direct and indirect effects working to depress equity prices and to increase the premium on the emerging economy's equity. The direct effect is driven by fire-sales of equity in which domestic agents engage to meet margin calls. The indirect effect is induced by the larger consumption volatility and negative covariance between consumption and equity returns that results from the reduced ability to smooth consumption in the presence of present or future margin calls.

When domestic agents rush to sell equity to meet margin calls they deal with foreign traders that have a less-than-infinitely-elastic demand for equity because of trading costs. As a result, equity prices drop below their fundamentals level and the equity premium rises. These results require both the margin constraint on domestic agents and the trading costs on foreign firms. The collateral constraint on the small open economy is necessary but not sufficient to induce asset price collapses and Sudden Stops.

The initial margin call triggers a Fisherian asset-price deflation as the fall in equity prices leads to subsequent rounds of margin calls. If the domestic economy is not highly leveraged (i.e., if it has a low debt-equity ratio), the asset-price deflation and large portfolio re-allocations take place without impairing too much the domestic agent's ability to smooth consumption. In contrast, if foreign debt is high relative to equity holdings, asset prices fall less and portfolio shifts are smaller but the emerging economy suffers a collapse in consumption and a large reversal in the current account deficit. 
The analysis of this paper is incomplete in several key respects. First, it is important to add other sources of uncertainty affecting emerging economies that can also trigger Sudden Stops (shocks to the world interest rate and policy shocks are two obvious choices). Second, the model abstracts from capital accumulation decisions which can act to increase the persistence of Sudden Stops. Third, since the model considers only one good it abstracts from the "liability dollarization" feature of foreign debt contracts of emerging economies denominated in units of tradable goods but leveraged on the income and assets of the nontradables sector. Fourth, if this paper's account of Sudden Stops driven by world capital market frictions is realistic, it could be possible to design welfare-improving official lending facilities to address them.

Recent research is filling some of these gaps. Cavallo, Perri, Roubini and Kisselev (2002) adopt the model of this paper to a two-sector environment and study the interaction of margin constraints and 'over-reaction' in real exchange rates. Arellano and Mendoza (2002) consider capital accumulation with adjustment costs by linking the margin constraint to a Tobin's-q valuation of physical capital. Finally, in work in progress Mendoza examines the potential benefits of ex ante official asset price guarantees targeted at offseting the effects of the margin calls and trading costs identified in this paper. The goal is to determine how best to trade off these benefits against the moral hazard incentives that the official provision of price guarantees would create. 


\section{References}

Aghion, Philippe, Philippe Bacchetta, and Abhijit Banerjee, (2000), "Currency Crises and Monetary Policy with Credit Constraints," mimeo, Dept. of Economics, Harvard University.

Aiyagari, S. Rao (1993), "Explaining Financial Market Facts: The Importance of Incomplete Markets and Transaction Costs." Federal Reserve Bank of Minneapolis Quarterly Review 17, 17 31.

(1994), "Uninsured Idiosyncratic Risk and Aggregate Saving," Quarterly Journal of Economics, 109(3), 659-684.

and Mark Gertler, (1999), “'Overreaction’ of Asset Prices in General Equilibrium,” Review of Economic Dynamics, 2, 3-35.

Auernheimer, Leonardo and Roberto Garcia-Saltos (2000), "International Debt and the Price of Domestic Assets,” IMF Working Paper No. WP/00/177, International Monetary Fund.

Backus, David K., Allan W. Gregory and Stanley E. Zin, (1989), "Risk Premiums in the Term Structure: Evidence from Artificial Economies," Journal of Monetary Economies, 24, 371-400.

Bernanke, Ben, Gertler, Mark and Simon Girlchrist, (1998), "The Financial Accelerator in a Quantitative Business Cycle Framework." NBER Working Paper No. 6455, National Bureau of Economic Research, Cambridge: MA.

Caballero, Ricardo J. and Arvind Krishnamurthy, (1999), "Emerging Markets Crises: An Asset Markets Perspective.” Mimeo, Sloan School of Business, MIT, Cambridge: MA.

Calvo, Guillermo A., (1998), “ Capital Flows and Capital-Market Crises: The Simple Economics of Sudden Stops," Journal of Applied Economics, v. 1, pp. 35-54

, and Carmen M. Reinhart (1999), "When Capital Inflows come to a Sudden Stop:

Consequences and Policy Options," mimeo, Center for International Economics, Department of Economics, University of Maryland.

, and Enrique G. Mendoza (2000a), "Capital-Markets Crises and Economic Collapse in

Emerging Markets: An Informational-Frictions Approach," American Economic Review: Papers and Proceedings, May.

, and Enrique G. Mendoza (2000b), "Rational Contagion and the Globalization of Securities Markets," Journal of International Economics, v. 51.

Cavallo, Michelle, Fabrizio Perri, Nouriel Roubini and Kate Kisselev (2002), "Exchange Rates Overshooting and the Costs of Floating," mimeo, New York University. 
Cespedes, Luis, Roberto Chang and Andres Velasco, (2001) "Balance Sheets and Exchange Rate Policy." Mimeo, Department of Economics, New York University.

Christiano, Lawrence J., Christopher Gust and Jorge Roldos, (2001), "Monetary Policy in an International Financial Crisis." mimeo, Research Department, International Monetary Fund.

Coen-Pirani, Daniele (2000), "Margin Requirements and Equilibrium Asset Prices," mimeo, Graduate School of Industrial Administration, Carnegie Mellon University.

Epstein, Larry G. (1983) "Stationary Cardinal Utility and Optimal Growth under Uncertainty", Journal of Economic Theory, 31, 133-152.

Fisher, Irving, (1933), “The Debt-Deflation Theory of Great Depressions,” Econometrica 1, 337 57.

Frankel, Jeffrey A. and Schmukler, Sergio (1996), "Country Fund Discounts and the Mexican Crisis of December 1994," Open Economies Review, Suppl. 1, 7, 551-84

Greenwood, Jeremy, Zvi Hercowitz and Gregory W. Huffman (1988) "Investment, Capacity Utilization and the Real Business Cycle", American Economic Review, June.

Heaton, John and Deborah J. Lucas (1996), "Evaluating the Effects of Incomplete Markets on Risk Sharing and Asset Pricing," Journal of Political Economy, 104, no. 3, 443-487.

International Monetary Fund, (1999), International Capital Markets, September, International Monetary Fund, Washington: DC.

Judd, Kenneth L., Felix Kubler and Karl Schmedders (2000), "Computational Methods for Dynamic Equilibria with Heterogeneous Agents," mimeo, Hoover Institution.

Keynes, John Maynard, (1932), "The Consequences to the Banks of the Collapse of Money Value." ch. 7 of Essays in Persuasion, Harcourt, Brace and Company: New York, NY.

Kiyotaki, Nobuhiro and John Moore, (1997), “Credit Cycles,” Journal of Political Economy, v. 105, 211-248.

Krusell, Per and Anthony A. Smith Jr., (1997), "Income and Wealth Heterogeneity, Portfolio Choice, and Equilibrium Asset Returns," Macroeconomic Dynamics, 1, 387-422.

Lane, Philip and Gian Maria Milesi-Ferretti (2002), “”, Journal of International Economics.

Lucas, Deborah J. (1994) "Asset Pricing with Undiversifiable Income Risk and Short Sales Constraints," Journal of Monetary Economics, 34, 325-41. 
Lane, Philip R. and Gian Maria Milesi-Ferretti, (2001), "The External Wealth of Nations: Measures of Foreign Assets and Liabilities for Industrial and Developing Countries," Journal of International Economics, 55, 263-294.

Mendoza, Enrique G., (1991), "Real Business Cycles in a Small Open Economy," American Economic Review, 81, 797-818,

(2002), "Credit, Prices, and Crashes: Business Cycles with a Sudden Stop," in Preventing Currency Crises in Emerging Markets, ed. by S. Edwards and J. Frankel, University of Chicago Press.

Obstfeld, Maurice (1982), “Aggregate Spending and the Terms of Trade: Is There a LaursenMetzler Effect," Quarterly Journal of Economics, , 97, 251-270.

Paasche, Bernhard, (2001), “Credit Constraints and International Financial Crises, " Journal of Monetary Economics, v.28, 623-650.

Telmer, Chris I. (1993), “Asset-Pricing Puzzles and Incomplete Markets," Journal of Finance, 48, 1803-1832. 
Table 1. Sudden Stops in Four Emerging Economies

\begin{tabular}{|c|c|c|c|}
\hline & $\begin{array}{c}\text { Equity Prices } \\
\text { (percent change) }\end{array}$ & $\begin{array}{l}\text { Current Account-GDP Ratio } \\
\text { (percentage points difference) }\end{array}$ & $\begin{array}{l}\text { Inustrial Production } \\
\text { (percent change) }\end{array}$ \\
\hline Argentina (94.4-95.1) & -26.83 & 4.05 & -9.26 \\
\hline Korea (97.4-98.1) & -35.30 & 10.97 & -7.20 \\
\hline Mexico (94.4-95.1) & -52.49 & 5.24 & -9.52 \\
\hline Russia (98.3-98.4) & -59.37 & 9.46 & -5.20 \\
\hline
\end{tabular}

Note: Equite price indexes are in U.S. dollars. The change in the current account-GDP ratio for Argentina corresponds to the second quarter of 1995. Industrial production figures for Korea and Russia are annual rates. 
Figure 1. Foreign Bond Decision Rule for Emerging Economy with and without Margin Requirements in the Low Productivity State (as functions of the $(\alpha, b)$ pairs in the discretized state space $Z$ )

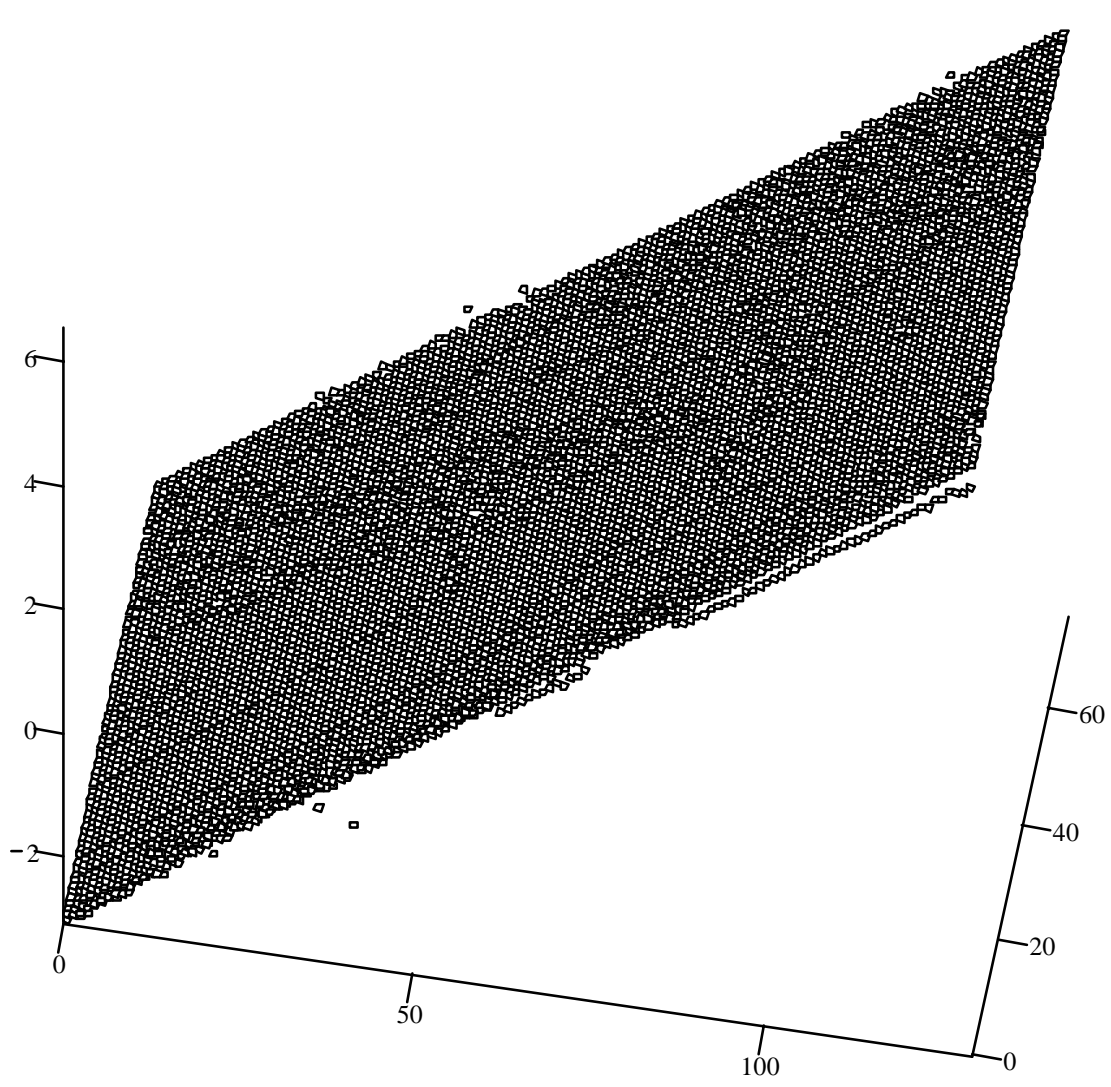

BP1

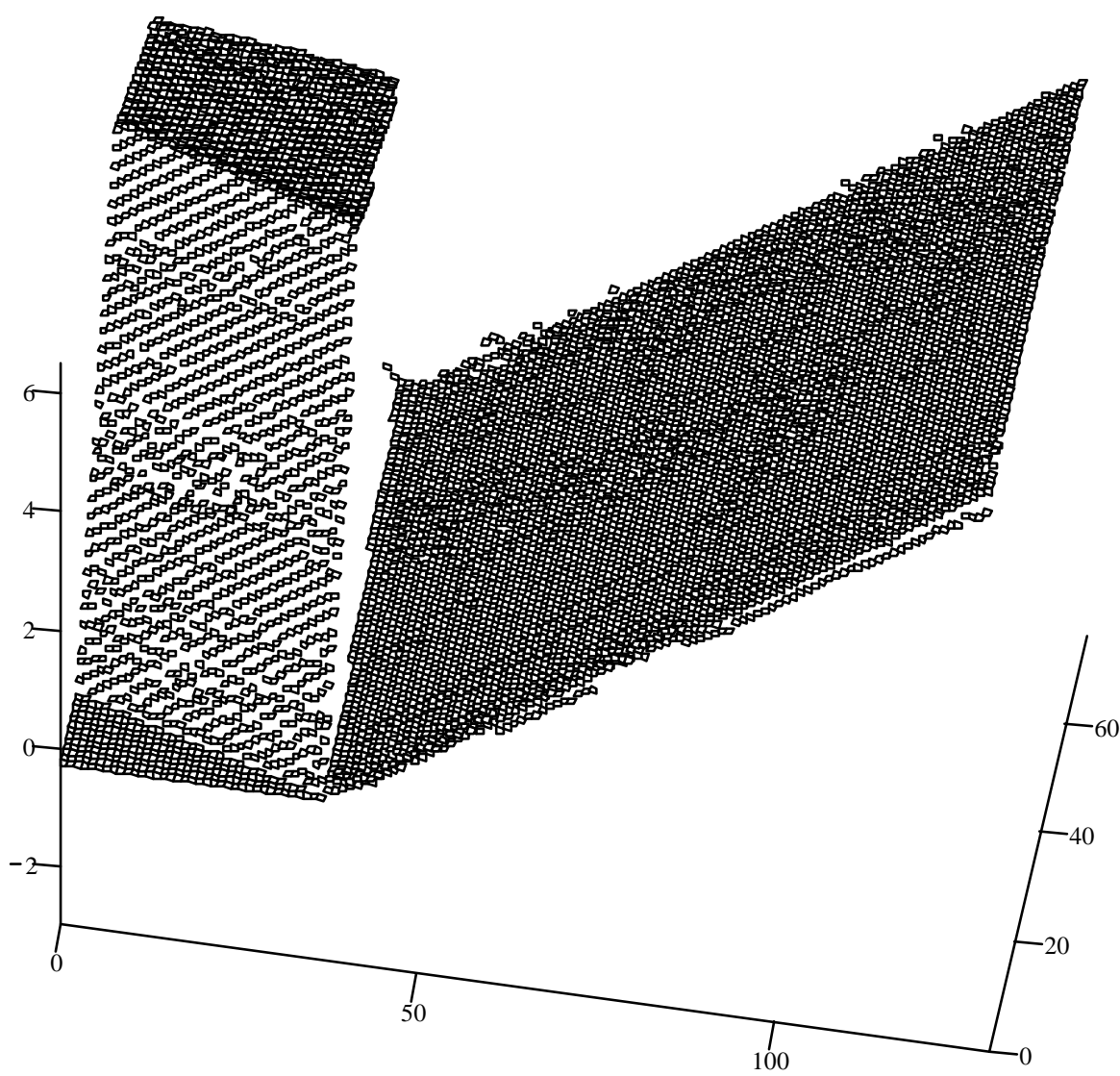

BP1b 
Figure 2. Equity Decision Rule of the Emerging Economy with and without Margin Requirements in the Low Productivity State (as functions of the $(\alpha, b)$ pairs in the discretized state space $\mathrm{Z}$ )

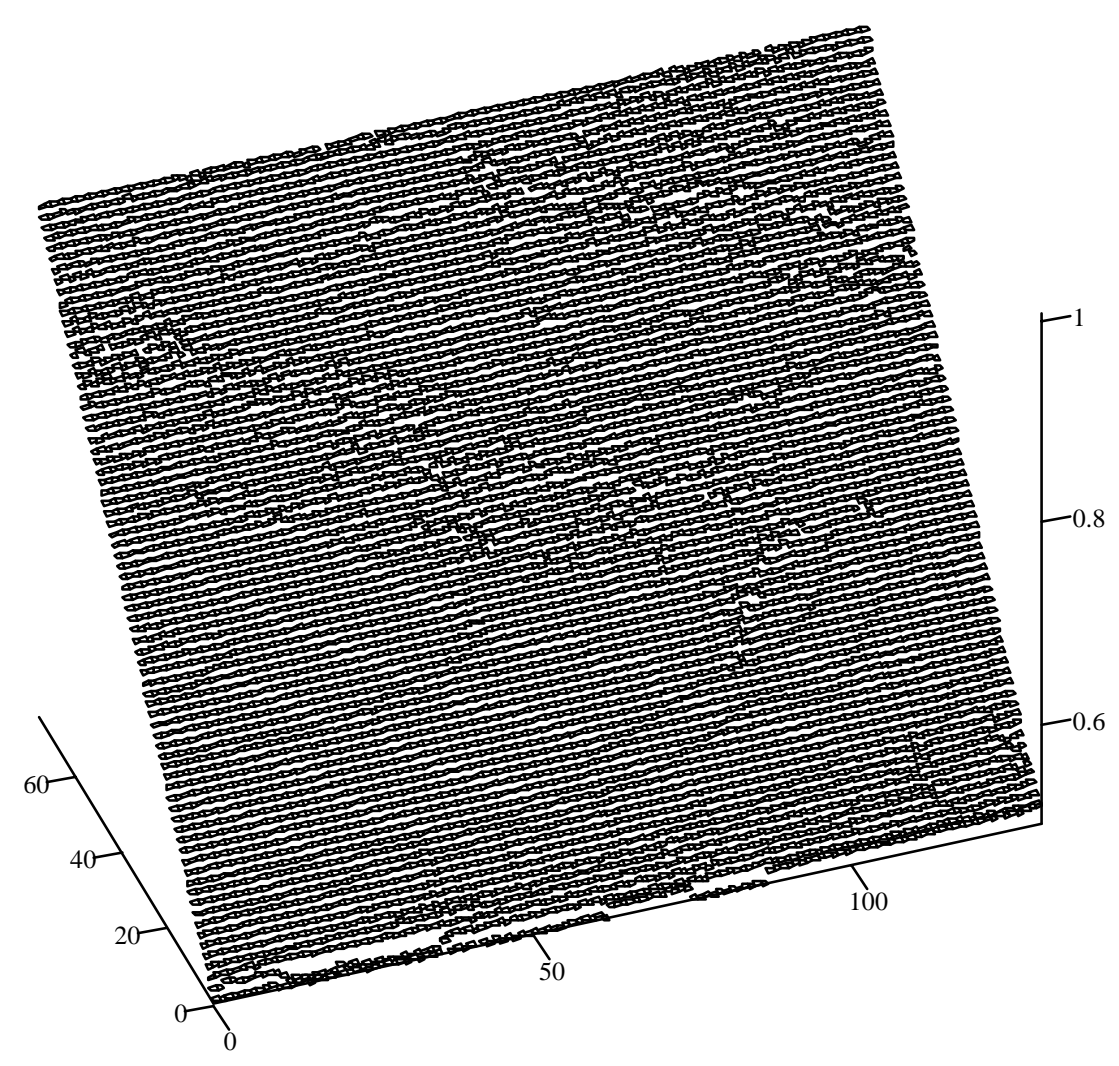

AP1

Without Margin Requirements

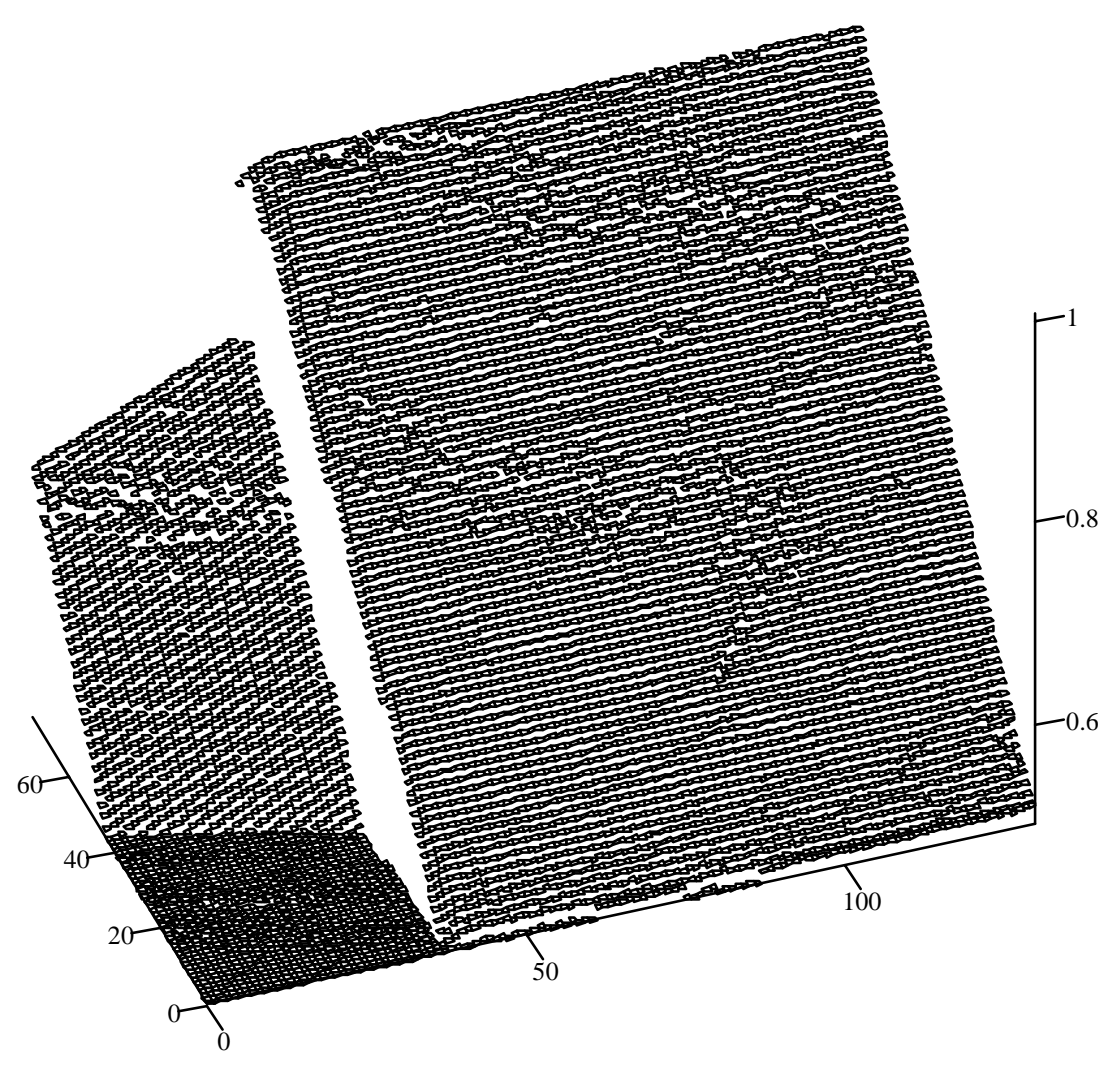

AP1b

With Margin Requirements 
Figure 3. Equity Prices for Emerging Economy with and without Margin Requirements in the Low Productivity State (as functions of the $(\alpha, b)$ pairs in the discretized state space $Z$ )

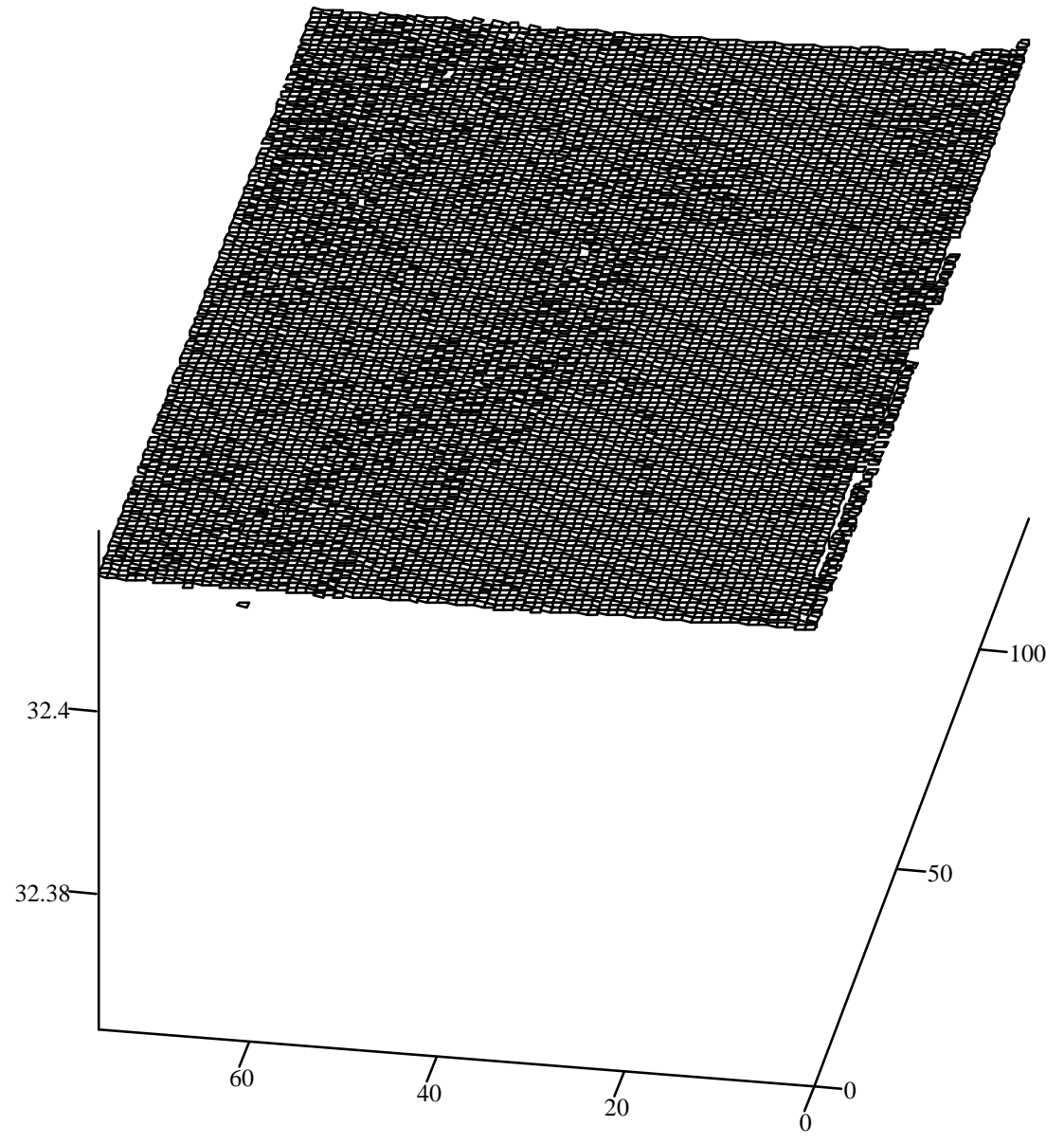

Q1

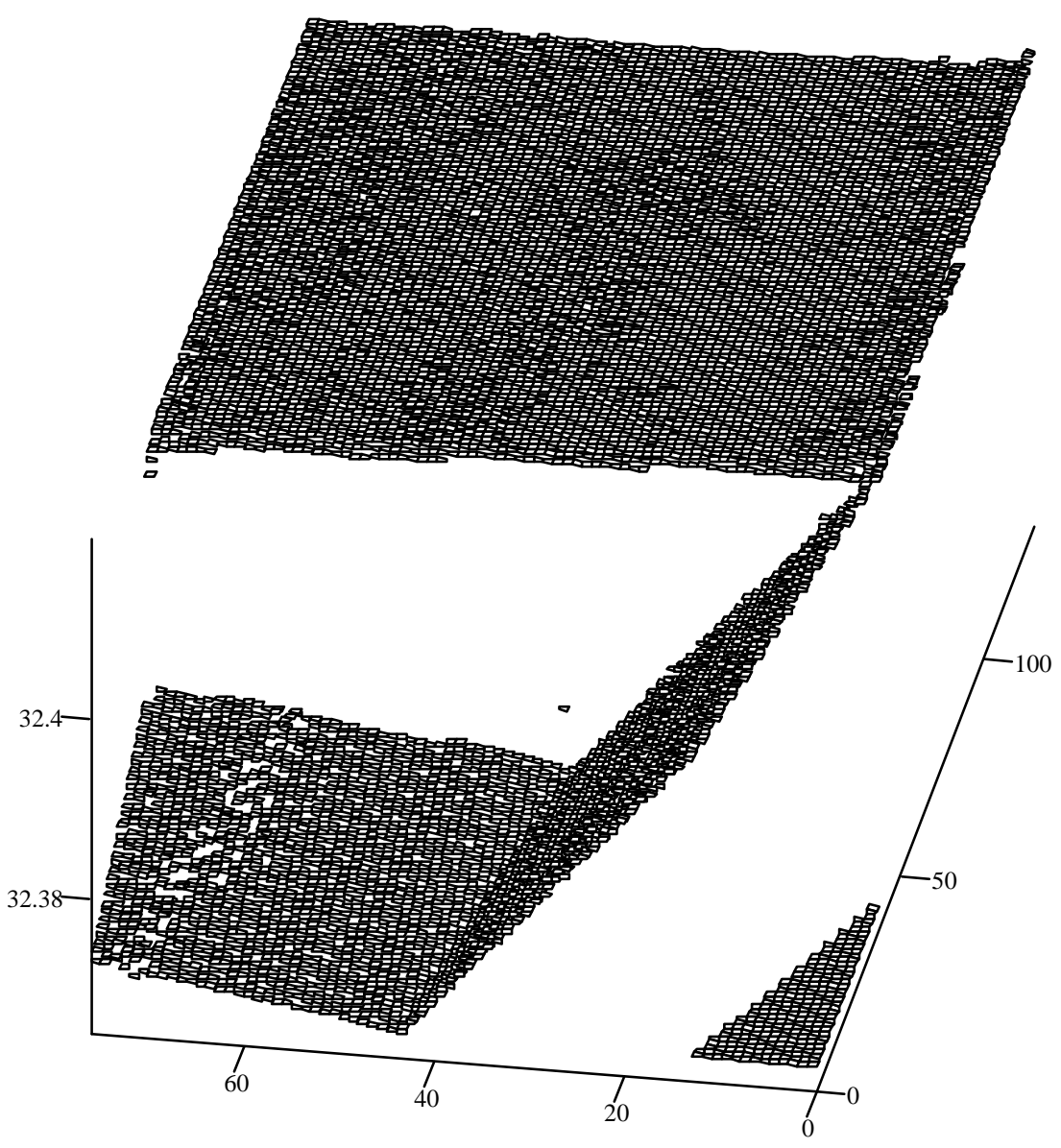

Q1b 
Figure 4. Premium on the Emerging Economy's Assets with and without Margin Requirements in the Low Productivity State (as functions of the $(\alpha, b)$ pairs in the discretized state space $Z$ )

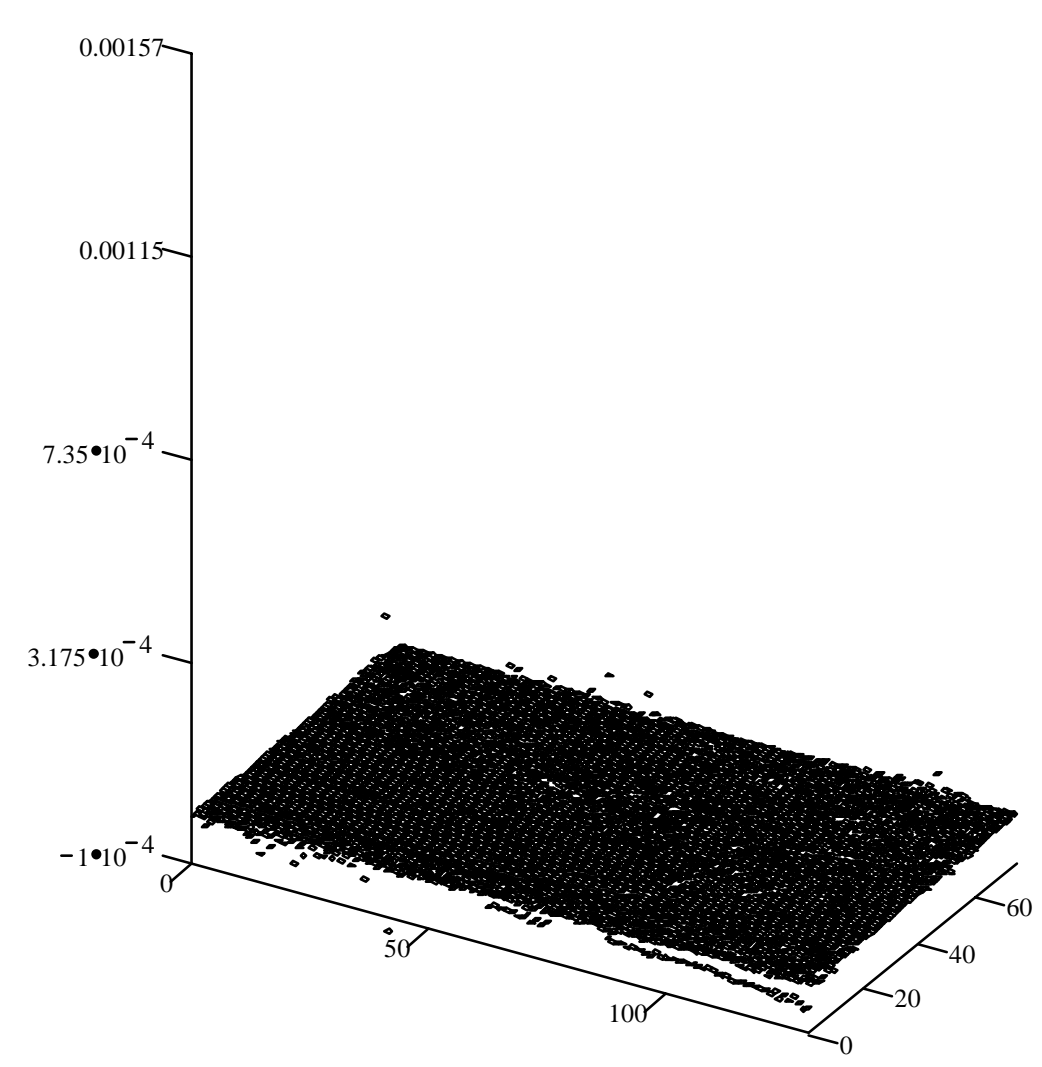

EQP1

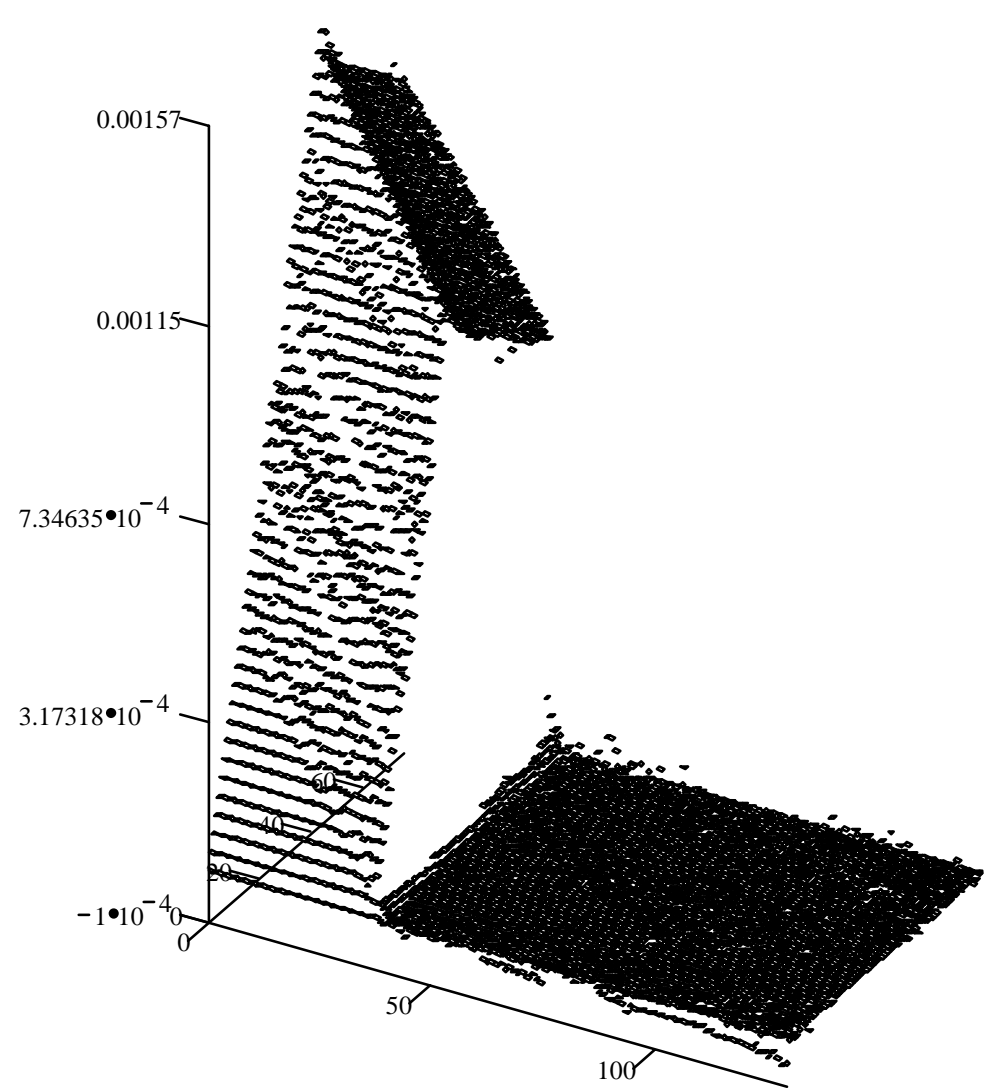

EQP1b 
Figure 5. Debt Equity Ratios for Economies with and without Margin Requirements in the Low Productivity State (as functions of the $(\alpha, b)$ pairs in the discretized state space $Z$ )

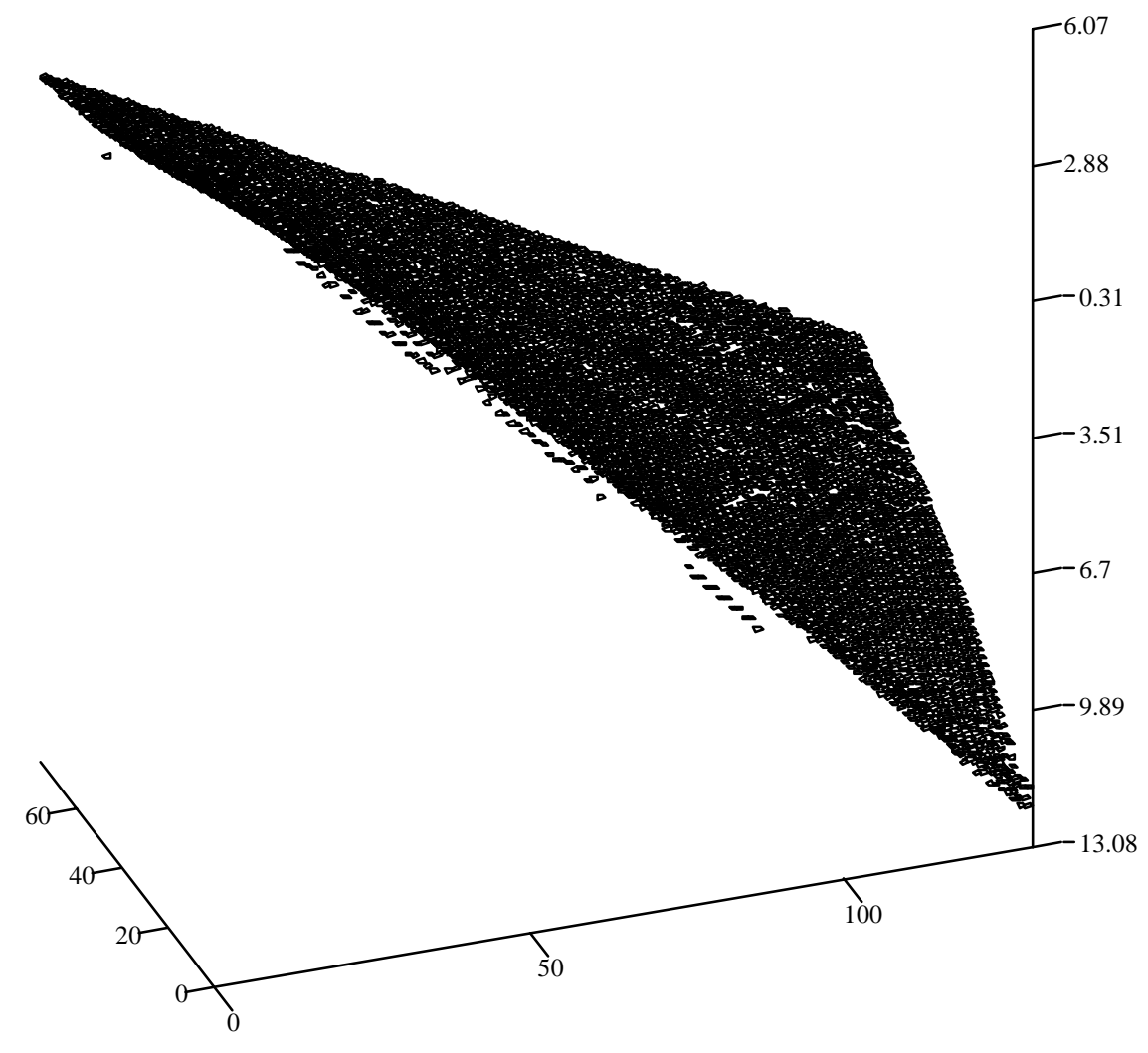

DEQR

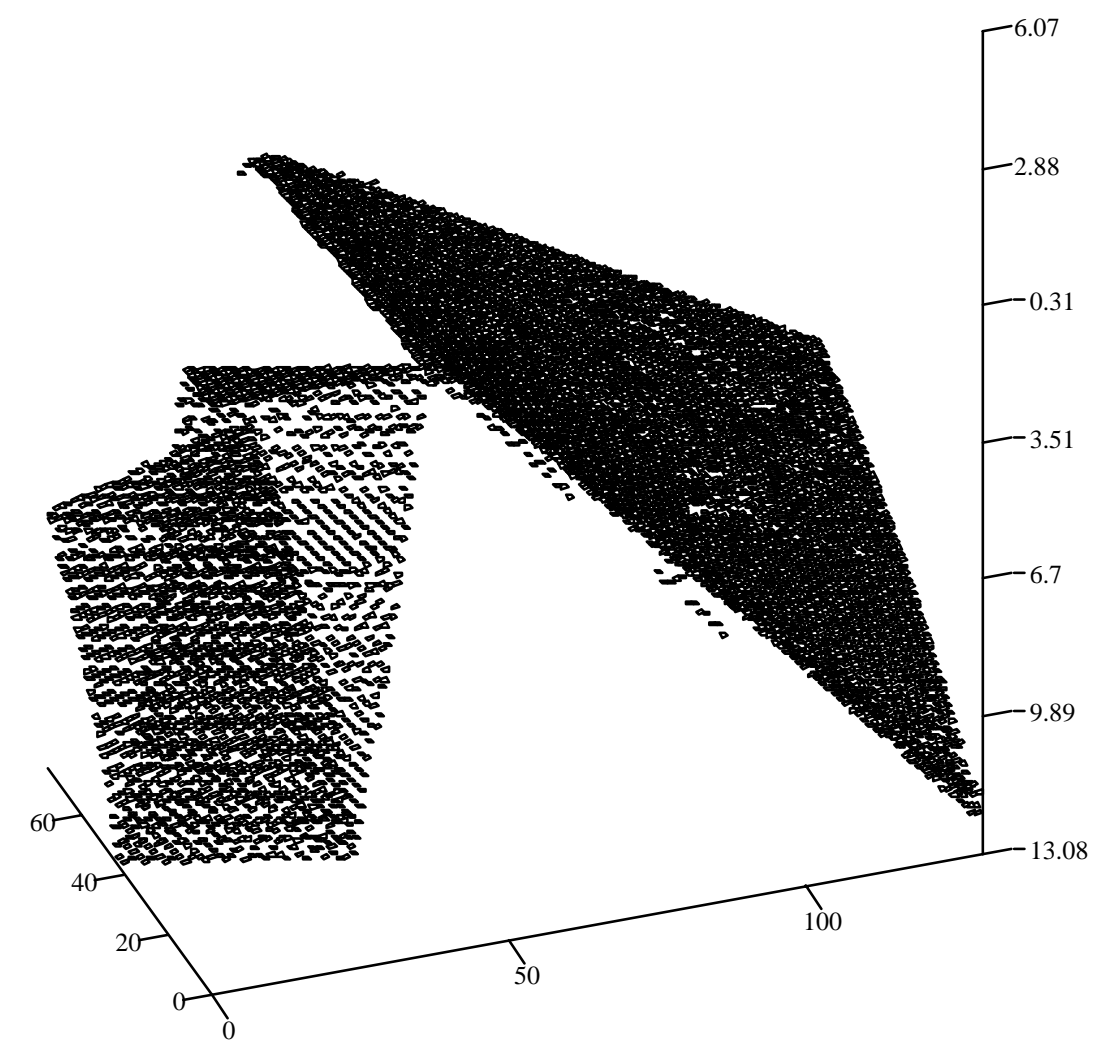

$\mathrm{DEQRb}$

With Margin Requirements 
Figure 6. Ergodic Cumulative Distribution Functions of Bonds and Equity Holdings in Economies with and without Margin Requirements
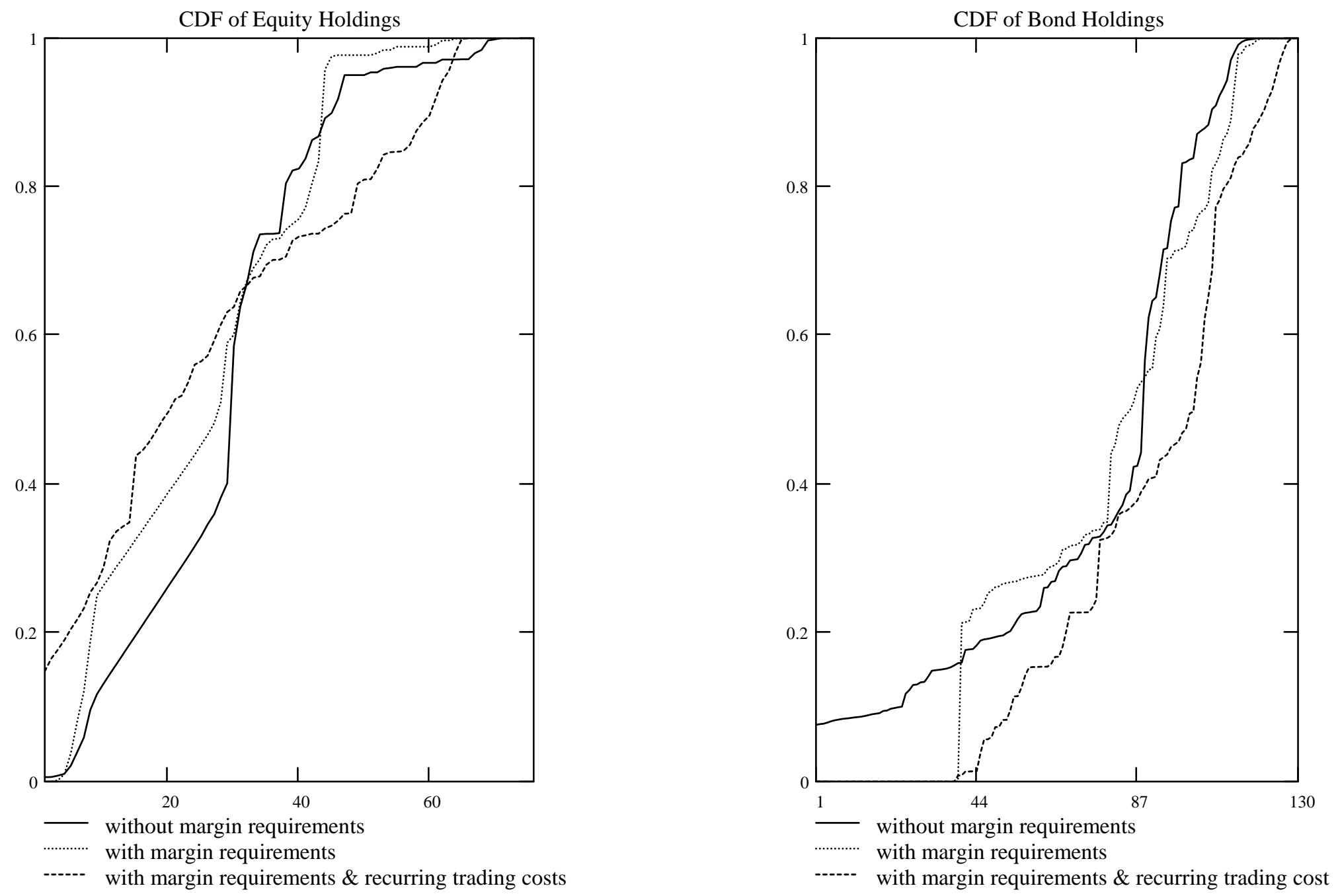
Figure 7. Impact Effect of a Productivity Shock on Consumption in the Margin Calls Region (as functions of the $(\alpha, b)$ pairs in the subset of the state space with margin calls)

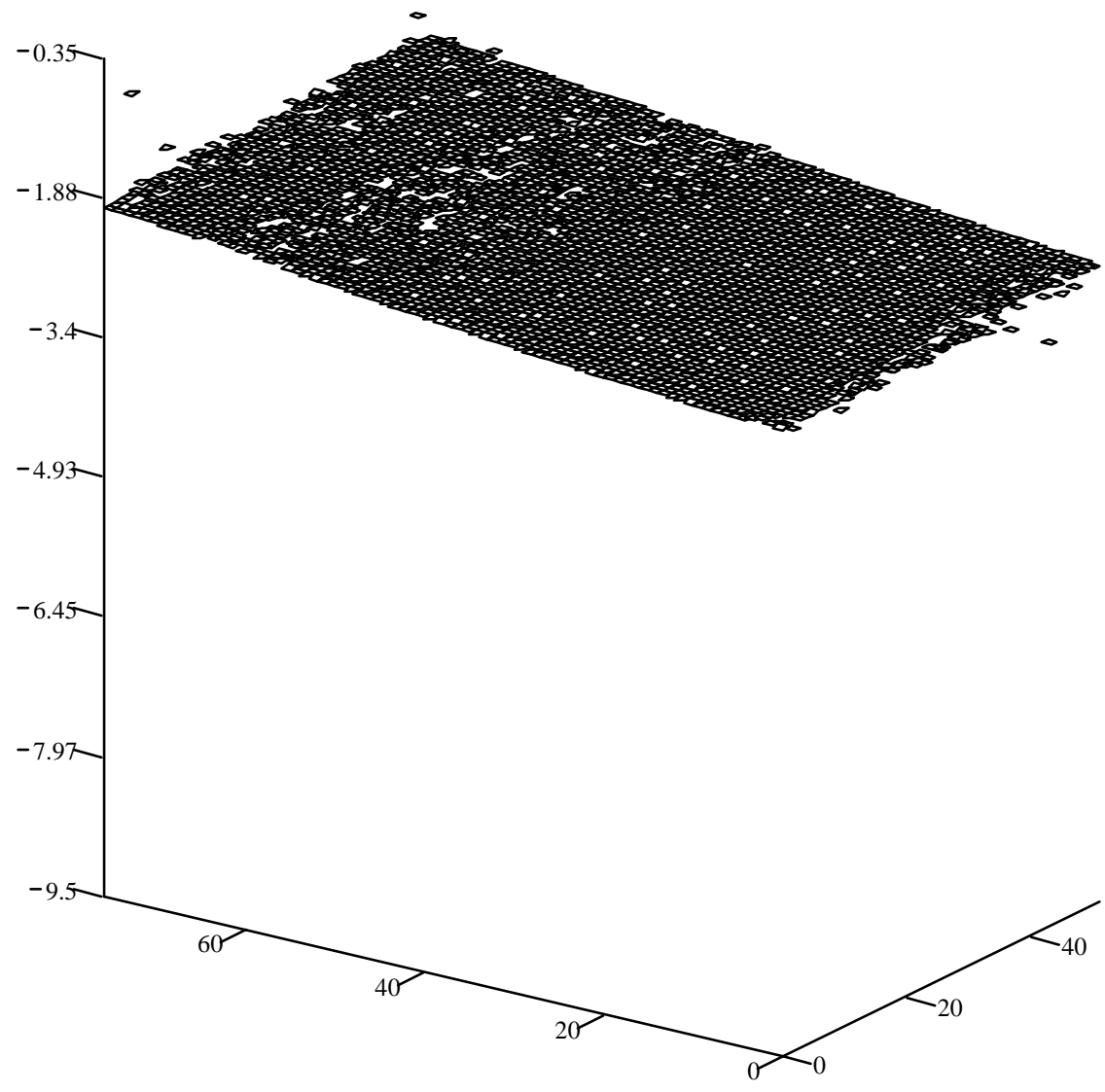

$\mathrm{xx}$

Without Margin Requirements

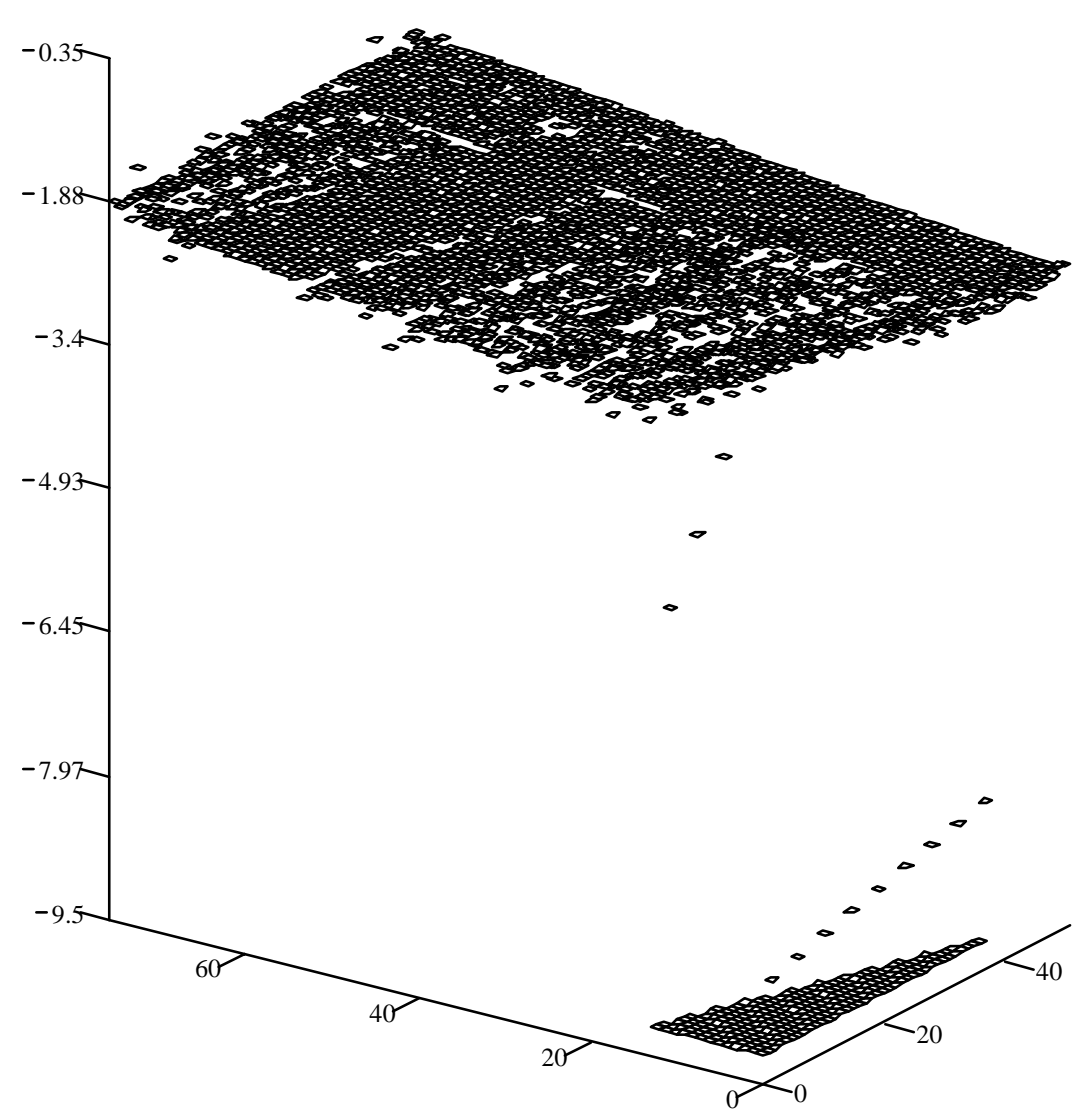

$\mathrm{xxb}$

With Margin Requirements 
Figure 8. Impact Effect of a Productivity Shock on the Current Account-Output Ratio in the Margin Calls Region (as functions of the $(\alpha, b)$ pairs in the subset of the state space with margin calls)

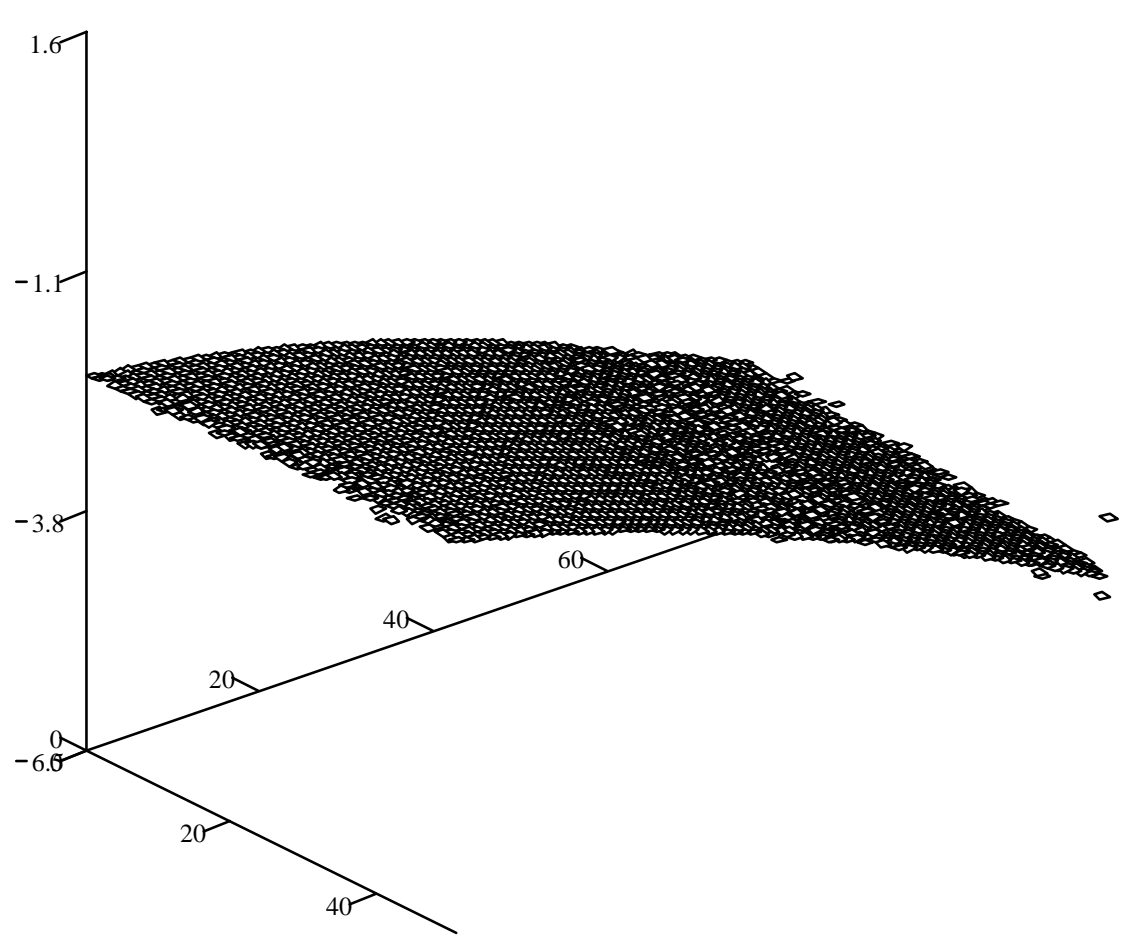

$\operatorname{cax}$

Without Margin Requirements

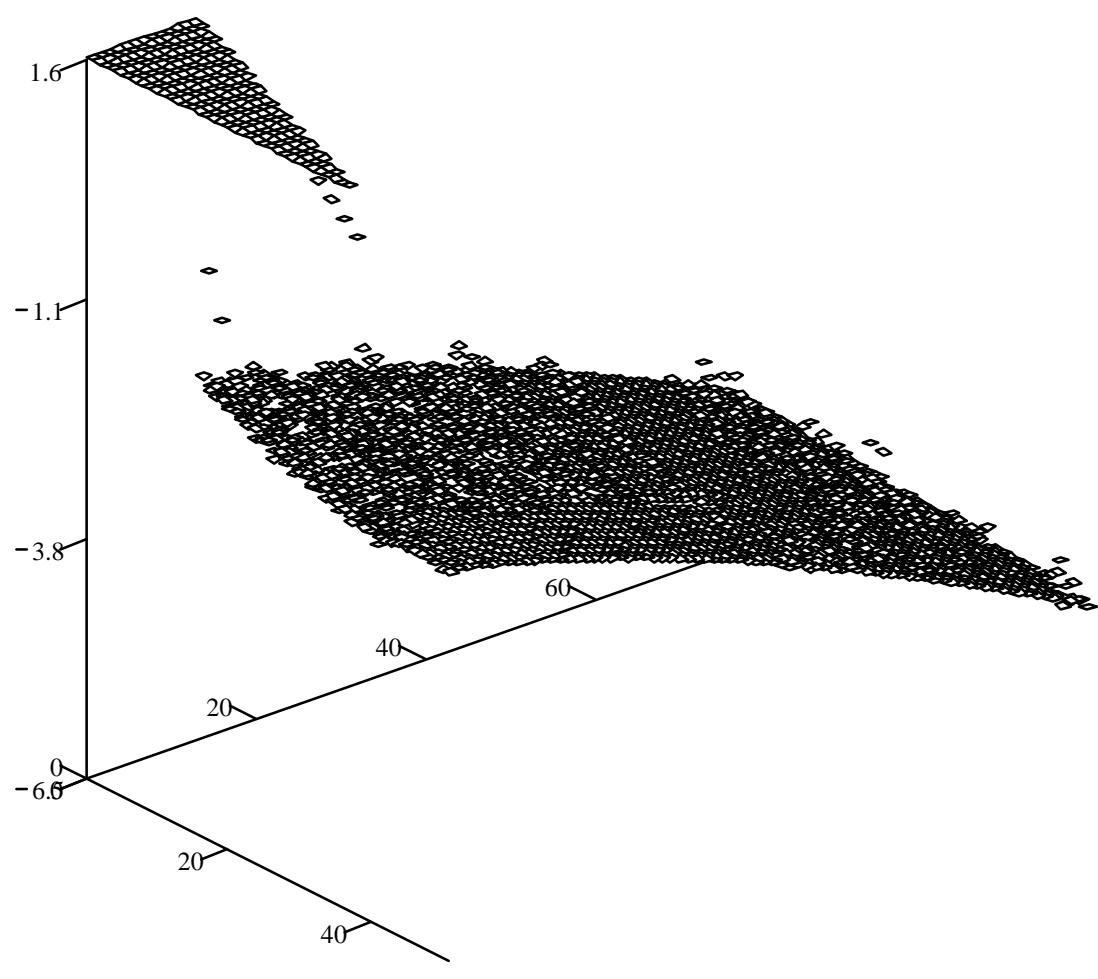

caxb

With Margin Requirements 